Marquette University

e-Publications@Marquette

$10-1-2017$

\title{
Perceptions of Institutional Quality: Evidence of Limited Attention to Higher Education Rankings
}

Andrew G. Meyer

Marquette University, andrew.meyer@marquette.edu

Andrew R. Hanson

Marquette University, andrew.r.hanson@marquette.edu

Daniel C. Hickman

University of Idaho

Accepted version. Journal of Economic Behavior \& Organization, Vol. 142 (October 2017): 241-258.

DOI. (C) 2017 Elsevier. Used with permission. 
Marquette University

e-Publications@Marquette

\title{
Economics Faculty Research and Publications/College of Business Administration
}

This paper is NOT THE PUBLISHED VERSION; but the author's final, peer-reviewed manuscript. The published version may be accessed by following the link in the citation below.

Journal of Economic Behavior \& Organization, Vol. 142, October (2017): 241-258. DOI. This article is (C) Elsevier and permission has been granted for this version to appear in e-Publications@Marquette. Elsevier does not grant permission for this article to be further copied/distributed or hosted elsewhere without the express permission from Elsevier.

\section{Perceptions of institutional quality: Evidence of limited attention to higher education rankings}

Andrew G. Meyer

Department of Economics, Marquette University, Milwaukee, WI

Andrew R. Hanson

Department of Economics, Marquette University, Milwaukee, WI

Daniel C. Hickman

College of Business and Economics, University of Idaho, Moscow, ID

\begin{abstract}
Rankings of colleges and universities provide information about quality and potentially affect where prospective students send applications for admission. We find evidence of limited attention to the popular U.S. News and World Report rankings of America's Best Colleges. We estimate that applications discontinuously drop by $2 \%-6 \%$ when the rank moves from inside the top 50 to outside the top 50 whereas there is no evidence of a corresponding discontinuous drop in institutional quality. Notably, the ranking of 50 corresponds to the first page cutoff of the printed U.S. News guides. The choice of college is typically a one-time decision with potentially large repercussions, so students' limited attention to rankings likely represents an irrational bias that negatively affects welfare.
\end{abstract}




\section{Keywords}

Higher education, Decision heuristics, Limited attention, Salience

\section{Introduction}

In contrast to standard economic models of rational decision makers in which individuals incorporate all information, economists and psychologists have uncovered multiple settings where individuals rely upon limited information to simplify complex decisions (DellaVigna, 2009). The bulk of this evidence originates from laboratory experiments, but there is growing empirical evidence that economic agents use these decision heuristics in uncontrived settings as well (for example, Busse et al., 2013, Chetty et al., 2009, Conlin et al., 2007, Finkelstein, 2009, Lacetera et al., 2012, Pope, 2009). Understanding how, why, and when decision makers deviate from standard economic models is important for a more complete understanding of behavior and for improving predictive ability of theoretical models.

We investigate how limited attention affects decision making in the context of applying for admission to institutions of higher education (IHEs); in particular, we examine how salient thresholds of IHE rankings (top 10, top 50, or top 100) affect student applications. ${ }^{1}$ The college application decision is of primary importance as it is typically only made once and has lifelong implications. ${ }^{2}$ To understand the effect of ranking salience on application behavior, we form a panel of IHEs by merging institutional information from the U.S. Department of Education IPEDS database with U.S. News and World Report (USNWR) rankings of national Liberal Arts Colleges and National Universities. We use the panel to test for discontinuous changes in applications at thresholds that may be most salient to students.

The ranking threshold of 50 may be particularly salient because it represents the last numerical ranking on the first page of IHE rankings in the printed version of the USNWR. We find evidence to support this theory; there is a robust discontinuity in the number of applications received by IHEs at the ranking threshold of 50 . Specifically, we find that applications discontinuously drop by $2 \%-6 \%$ when an IHE crosses over this threshold. Additionally, we present evidence that the discontinuity at the threshold of 50 is stronger in the earlier years of our sample relative to later years. Patterns in survey and Google search data imply a concurrent decrease in the relative importance of the printed USNWR guide in the later years of our sample, further supporting our claim that the physical page break matters. We also find weaker evidence of a similar discontinuity occurring at the threshold of 100 . These discontinuities in applications support a theory of limited attention to rankings and indicate that prospective students may form quality perceptions of IHEs using heuristic information processing. Our calculations suggest that potentially thousands of students have ultimately enrolled at IHEs with inferior rankings because of limited attention over our 10-year sample period.

We initially follow the Lacetera et al. (2012) approach to estimate discontinuities at multiple thresholds. We then utilize a regression discontinuity (RD) design to estimate the treatment effect of crossing the ranking threshold of 50. Specifically, we estimate nonparametric local linear regressions, which narrow the bandwidth to include only observations that are closer to the top-50 threshold. Results from these local linear regressions also show a discontinuous drop in applications when 
crossing the threshold of 50 that is robust to the RD inference suggested by Calonico et al., 2014a, Calonico et al., 2014b and Calonico et al., 2016a, Calonico et al., 2016b, Calonico et al., 2016c. Moreover, falsification tests do not show discontinuities at other rankings thresholds that should not matter for limited attention.

Our identification strategy addresses potential omitted variable bias that occurs because rank is correlated with quality, whereas previous studies may attribute IHE outcomes to the rank when IHE quality may be driving both IHE rank and IHE outcomes. ${ }^{3}$ Moreover, we are able to test for a discontinuous drop in IHE quality when crossing the threshold of 50. Alongside the more visible ordinal ranking - which determines treatment status - the USNWR provides a cardinal measure of IHE quality. We do not find any discontinuous drop in this cardinal overall score in crossing the USNWR threshold of 50. This further supports our claim that students are overreacting to the visibility of the top-50 in their application decisions.

Perhaps the most closely related study, Bowman and Bastedo (2009) find that moving onto the front page of the USNWR guide improves admissions outcomes including acceptance rate, incoming student quality, and number of applications for IHEs. However, their study period runs from 1997 to 2004. During this time period, USNWR only provided numerical rankings for the top 50 IHEs within a category. As such, their sample includes only the 56 National Universities and 56 national Liberal Arts Colleges that make it to the top-50 during this time. Furthermore, with no continuous ranking or measure of quality for IHEs outside of the top 50, it is difficult to separate the causal effect of rankings from the effects of unobserved quality differences.

Several recent studies have provided evidence on the causality of rankings or ratings on various outcomes. Pope (2009) identifies the causal effect of rankings on hospital admissions by exploiting plausibly exogenous changes in USNWR methodology. Luca and Smith (2013) likewise leverage changes in the USNWR methodology to estimate the causal impact of rankings on student application decisions. The authors show that an exogenous one-rank improvement in USNWR rankings leads to an approximate 1\%-2\% increase in applications. Anderson and Magruder (2012) utilize a regression discontinuity design to identify the effect of a more positive restaurant rating on availability and find a significant causal effect of receiving an extra one-half star from Yelp.com on availability of reservations at San Francisco restaurants.

Another group of studies provide evidence of behavioral biases in student behavior. ${ }^{4}$ Luca and Smith (2013) find that prospective students fail to use all available information because the salience of the USNWR rankings matters. Specifically, rankings have no effect on application decisions when rankings are presented in an alphabetically organized list. Luca and Smith (2015) provide evidence that IHEs recognize students may respond differently to information based on visibility. Among other findings, they show that business school websites often shroud information about their rankings and coarsen rankings information to state only a category of rankings such as "top 20."

As noted by DellaVigna (2009) and Lacetera et al. (2012), it is not clear if limited attention is a rational calculation under informational processing constraints or an irrational bias. Our results show that 
limited attention persists in the context of the college application decision. It is typically relatively low cost to apply to the marginal school on one's list. However, repercussions from omitting an application because of inattention could be large in terms of financial aid or eventual labor market outcomes. This suggests that, even if limited attention is boundedly rational, prospective students may not be allocating their limited attention in an optimal manner.

\section{Background and data}

Each September, the USNWR releases its annual rankings guide titled America's Best Colleges. These guides rank IHEs within the categories of "National Universities," "National Liberal Arts Colleges," "Regional Universities," and "Regional Colleges." Depending on the year, the guides also provide rankings according to specialty categories such as "Best Value Schools" or specific program such as "Finance." The most prominent and publicized categories are "National Universities" and "National Liberal Arts Colleges." Our study includes all ranked IHEs from these two categories over the years 2004-2013. Table 1 summarizes the rankings by category and year for our sample period. Depending on the year, the guides rank between 120 and 199 National Universities and between 104 and 187 national Liberal Arts Colleges. Remaining IHEs in these categories are listed alphabetically without a rank and are hence not part of our sample. Prior to 2004, the USNWR guides only ranked the top 50 IHEs so we do not include any observations from 2003 or earlier.

Table 1. US News Rankings Summary.

National Universities

(1)

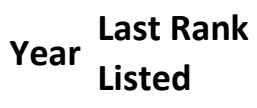

2004123

2005120

2006120

2007124

2008124

2009130

2010128

2011191

2012194

2013199
(2)

Last Rank on 1st Page

48

50

50

47

50

50

50

50

50

46
(3)

1st Rank on 2nd

Page

51

52

52

52

52

51

52

51

53

51

\section{Liberal Arts Colleges}

(4) (5)

\begin{tabular}{|c|}
\hline $\begin{array}{l}\text { Last Rank } \\
\text { Listed }\end{array}$ \\
\hline 106 \\
\hline 105 \\
\hline 104 \\
\hline 104 \\
\hline 122 \\
\hline 122 \\
\hline 122 \\
\hline 187 \\
\hline 178 \\
\hline 178 \\
\hline
\end{tabular}

Last Rank on 1st 1st Rank on 2nd
Page Page

$50 \quad 52$

$50 \quad 51$

$49 \quad 51$

$48 \quad 51$

$49 \quad 52$

$49 \quad 53$

$49 \quad 53$

$47 \quad 51$

$49 \quad 51$

$49 \quad 52$

There is previous evidence that a substantial portion of students consider these rankings when deciding where to apply and/or enroll. ${ }^{5}$ The USNWR rankings are the most widely circulated IHE rankings in the United States (Gnolek et al., 2014; Griffith and Rask, 2004) so prospective students are more likely to see these rankings relative to others. Pryor et al. (2009) report that $18.5 \%$ of first-time, full-time, first-year students say "rankings in national magazines" are "very important" in their decision 
of which particular college to attend. Yet there is reason to suspect that students may not process the rankings information perfectly. Higher education is a costly service where prospective students must simultaneously consider many complex attributes. For example, Pryor et al. (2009) reports 16 factors that at least $5 \%$ of first-time, full-time, first-year students choose as "very important" in deciding to attend a particular college. Psychologists and behavioral economists have theorized that individuals process only a subset of information to simplify complex decisions (DellaVigna, 2009) so students may focus on only the most salient features of rankings information. Furthermore, a growing body of research suggests that prospective college students may be particularly susceptible to behavioral biases in the context of the college application and attendance decision. ${ }^{6}$ DellaVigna (2009) proposes a simple model of limited attention to motivate strategies to test for inattention; one such strategy is to test whether consumer behavior changes based upon the salience of an opaque component of a good's value. Thus, in our context, we are theorizing that crossing over certain rankings thresholds is more salient to prospective students than marginal changes in rankings that do not cross such thresholds.

As previously mentioned, a crucial aspect of the print editions of America's Best Colleges is that there is always a page break separating IHEs that are ranked in the top 50 from IHEs ranked at 51 or worse. Table 1 shows the last rank appearing on the first page of the rankings and the first rank appearing on the second page of rankings. Specific numerical ranking values are sometimes missing because of ties. IHEs ranked at 50 or better are more visible in the printed guide relative to those ranked 51 or worse because of this page break. The threshold of 50 is likely the most important because of the structure of the guides, but other thresholds may matter also. IHEs sometimes identify themselves as a "top 10" or "top 100" institution. ${ }^{7}$ For example, Luca and Smith (2015) document some evidence of this kind of shrouding behavior among business schools. These thresholds may also be important simply because of informational processing heuristics if cutoffs of 10 or 100 are more salient than other rankings.

USNWR collects data on many dimensions, assigns a weight to each measure, and produces a composite weighted quality score. ${ }^{8}$ The composite score takes on a value between 0 and 100 and is displayed only according to an integer value. This integer score which carries some cardinal information about quality differences is then used to create an ordinal rank for the IHEs. The ordinal rank is the most visible information because it is bolded or highlighted in color and because IHEs are listed in table form according to this ordinal rank. Because the rankings preserve an ordinal measure of quality, we would expect IHEs with better rankings to receive more interest from students and hence more applications. However, a discontinuous drop in applications without a discontinuous drop in IHE quality at a rankings threshold provides evidence of limited attention.

We merge two data sources for our analysis, the U.S. IPEDS database and the print editions of America's Best Colleges (U.S. News \& World Report, 2004-2013). The outcome variable utilized in our analysis, the number of applications an IHE receives, is collected from the IPEDS database that contains a large quantity of information for each institution. Each IHE directly reports this information via annual surveys conducted by the National Center for Education Statistics (NCES). Any IHE that participates in any federal financial assistance program is required to complete these surveys. The variable we focus on is the number of first-time degree/certificate-seeking undergraduate students 
who applied for admission to an institution for the fall period. This information is collected for the fall periods of 2003-2013..$^{9}$ Additionally, we use IPEDS to record the sector and Carnegie classification ${ }^{10}$ for each IHE, and to collect data on the number of applicants that were admitted and the number enrolled for each fall period. We match the USNWR rankings that are released in September of a given year to the applications received in the following fall period. For example, the 2005 edition of America's Best Colleges was released in September 2004; these rankings are matched to applications received for fall 2005.

Merging IPEDS data with the USNWR rankings produces a sample size of 2696 IHE-year observations. We further restrict our sample to IHEs that report applications to IPEDS in the prior year because we condition on this lagged variable in our empirical strategy; this restricts the sample to $2613 \mathrm{IHE}$-year observations. Table 2 displays descriptive statistics on applications, first-year enrollment, and the admit rate for several groupings of USNWR rankings. Panel A shows that average applications fall as the USNWR ranking worsens for both National Universities and for Liberal Arts Colleges. However, the decline in applications is more pronounced for Liberal Arts Colleges. For example, there are approximately 44\% fewer average applications for Liberal Arts Colleges ranked $51-100$ relative to applications for Liberal Arts Colleges ranked in the top 50. The analogous decline for National Universities is approximately $20 \%$. Panel B shows that there is less variability in full-time first-year enrollment across the various groupings of rankings. Average first-year enrollment for Liberal Arts Colleges ranked 51-100 is approximately $18 \%$ lower than the average for Liberal Arts Colleges ranked in the top 50. Moreover, average enrollment is actually higher for National Universities ranked 51-100 relative to those ranked in the top 50 . The admit rate, shown in Panel C, largely explains the discrepancies between applications and enrollment. Better ranked IHEs are more selective in which students they admit.

Table 2. Descriptive Statistics by Rank.

\begin{tabular}{|c|c|c|c|c|c|c|}
\hline \multirow[b]{2}{*}{ Rank } & \multicolumn{3}{|c|}{ National Universities } & \multicolumn{3}{|c|}{ Liberal Arts Colleges } \\
\hline & Mean & Median & Std. Dev. & Mean & Median & $\mathbf{C}$ \\
\hline \multicolumn{7}{|c|}{ Panel A: Applications } \\
\hline 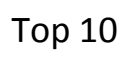 & 21 & 2 & $7,870.2$ & 5,4 & & 1 \\
\hline 0 & 23,5 & 6 & $12,458.4$ & 4 & 5 & $1,767.1$ \\
\hline 51-100 & $18,840$. & 818,939 & $9,699.1$ & $2,792.9$ & $92,455.5$ & 1543.9 \\
\hline 100 & 12,021 & 911,207 & $7,861.6$ & $2,614.4$ & 42232 & 1740.6 \\
\hline
\end{tabular}

Panel B: Full-time First-year Enrollment

\begin{tabular}{|c|c|c|c|c|c|c|}
\hline op 10 & 1,451 & 1391 & 500.1 & 470.4 & 482.5 & 10 \\
\hline r & $2,600.4$ & 1659 & $1,842.3$ & 526.1 & 504 & 552 \\
\hline 1 & 5.2 & 3458 & $2,013.8$ & 432.3 & 417.5 & 66.4 \\
\hline 100 & $2,600.2$ & 2498 & $1,606.3$ & 392.4 & 373 & 182.2 \\
\hline \multicolumn{7}{|c|}{ Panel C: Admit Rate } \\
\hline & 27 & 10.94 & 4.86 & 22.64 & 21.60 & 6.42 \\
\hline$p 5$ & 2.15 & 29.44 & 17.59 & 35.75 & 34.21 & 13.1 \\
\hline
\end{tabular}




\begin{tabular}{lcccccc} 
& \multicolumn{2}{c}{ National Universities } & \multicolumn{3}{c}{ Liberal Arts Colleges } \\
Rank & Mean & \multicolumn{2}{c}{ Median Std. Dev. Mean } & Median Std. Dev. \\
$51-100$ & 61.56 & 61.99 & 14.79 & 64.33 & 65.38 & 14.42 \\
$>100$ & 70.39 & 72.04 & 13.38 & 68.24 & 68.99 & 12.81
\end{tabular}

Fig. 1 plots applications against the USNWR ranking for National Universities and Fig. 2 provides the same plot for national Liberal Arts Colleges. In each case, we create bins with a width of 2 and plot the average number of applications within each bin. For example, we average all of the observations on applications for IHEs ranked at 1 or 2 and plot this as one point. In both figures, there is an inverse relationship between ranking and average applications. This is what we would expect if ranking is a proxy for quality; applications fall as quality decreases. Vertical lines designate the first rank for which an IHE has crossed over an important threshold (10,50, and 100). Visually, there appears to be a discontinuity at crossing the threshold of 50 in both figures, although it is starkest in Fig. 2 . There is not a clear indication of a discontinuity when crossing over 10 in either figure, but Fig. 1 (National Universities) appears to display a discontinuity when crossing the threshold of 100.

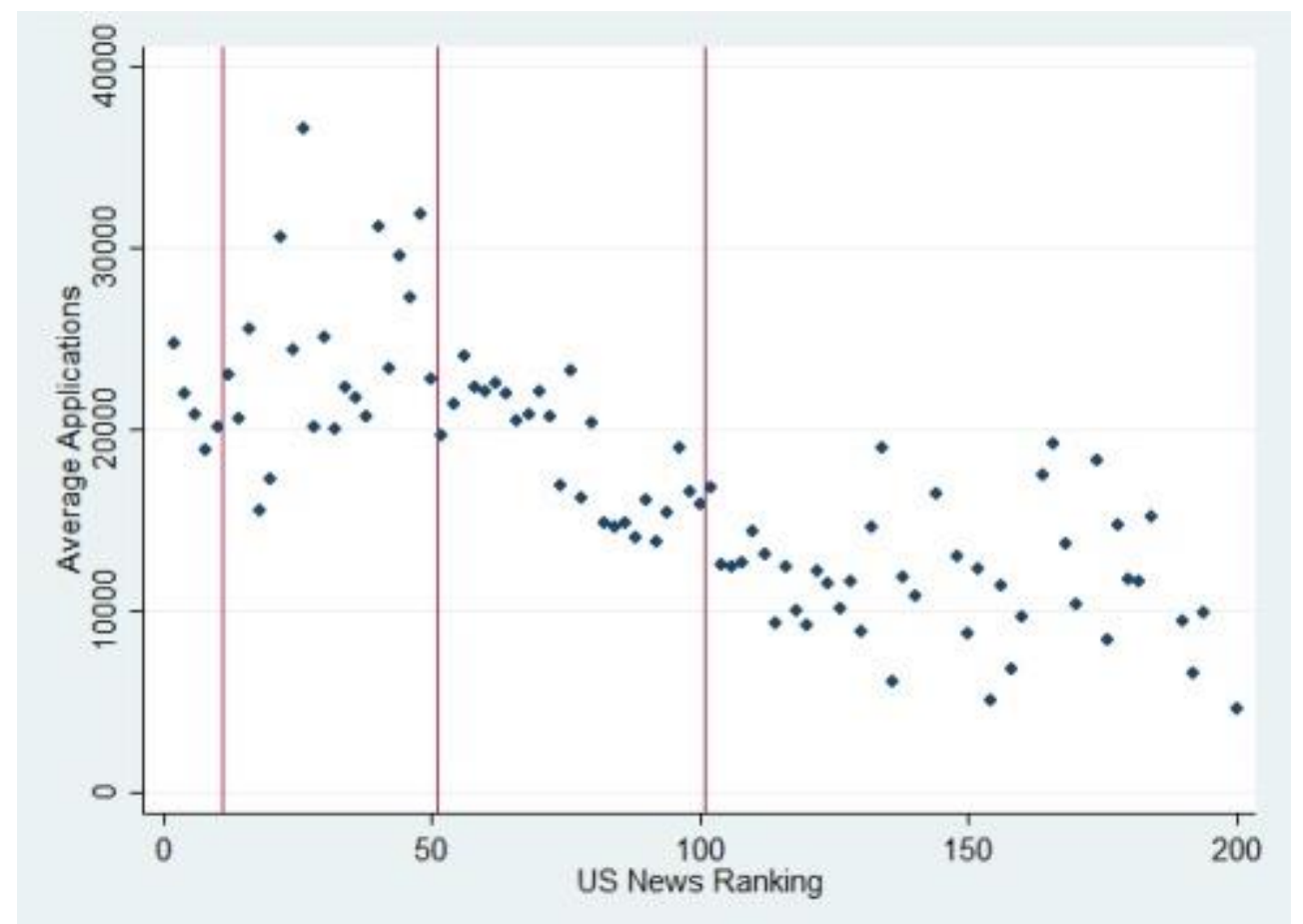

Fig. 1. Applications vs. Rank for National Universities.

Notes: This figure shows average applications by USNWR Ranking for all IHEs in the National University classification. The bin width equals 2 . Vertical lines indicate the first ranking for which a threshold has been crossed $(11,51,101)$. 


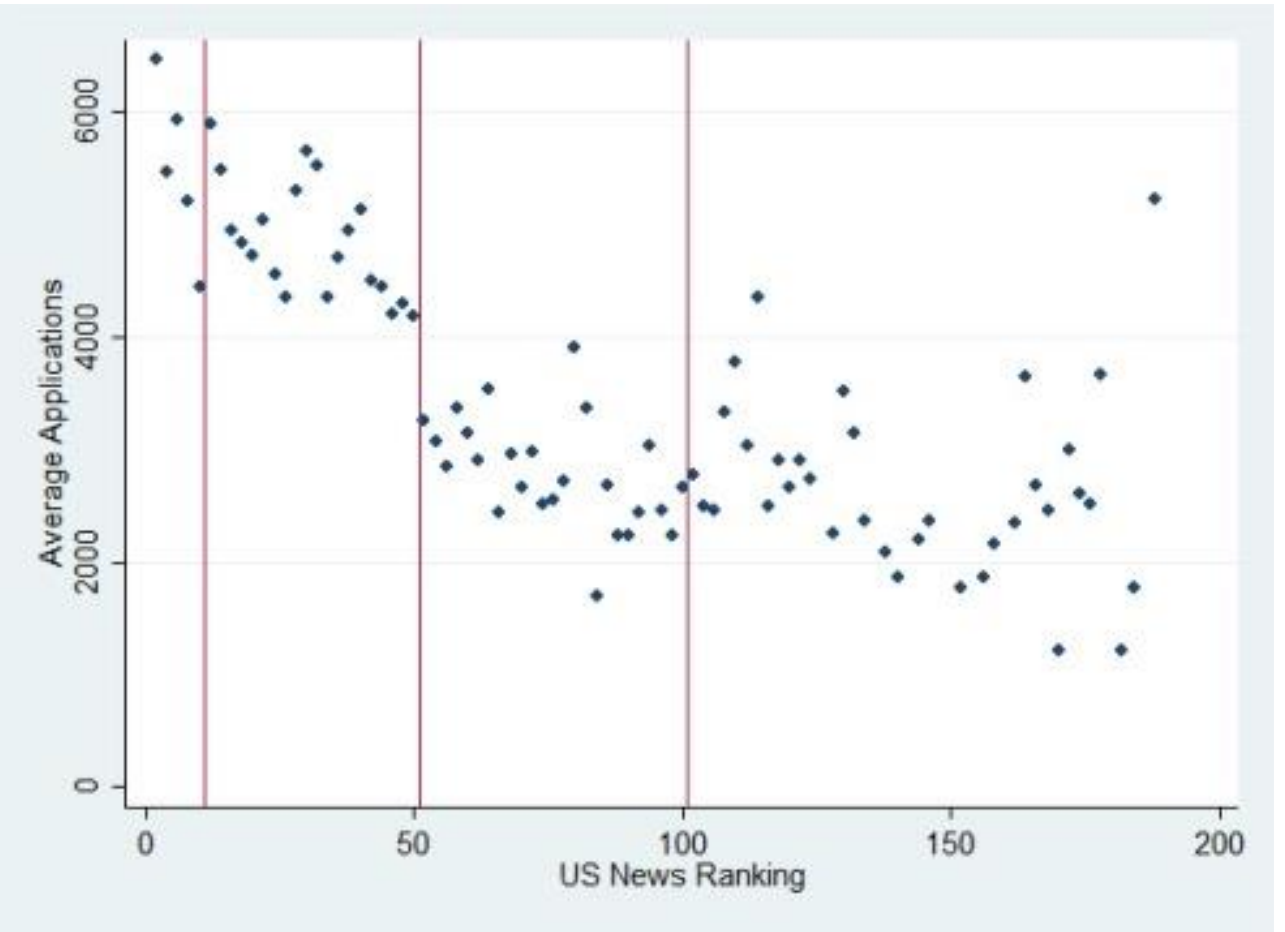

Fig. 2. Applications vs. Rank for National Liberal Arts Colleges.

Notes: This figure shows average applications by USNWR Ranking for all IHEs in the national Liberal Arts College classification. The bin width equals 2 . Vertical lines indicate the first ranking for which a threshold has been crossed $(11,51,101)$.

\section{Empirical strategy and results}

\subsection{Parametric regressions}

We begin with a regression analysis based on Lacetera et al. (2012). This method is similar to a regression discontinuity design because it flexibly controls for smooth changes in applications as an IHE falls in the rankings and estimates discontinuous changes in applications at certain thresholds. We test for discontinuities in the natural log of applications (Inapp) at the potentially important rankings thresholds of 10,50 , and 100 in the following regression specification:

$\operatorname{lnapp}_{i t}=\alpha+f\left(\operatorname{rank}_{i t}\right)+\beta_{10} I\left[\operatorname{rank}_{i t}>10\right]+\beta_{50} I\left[\operatorname{rank}_{i t}>50\right]+\beta_{100} I\left[\operatorname{rank}_{i t}>100\right]+$ $\gamma X_{\mathrm{it}}+\varepsilon_{i t}$

where $I($.$) is the indicator function and \boldsymbol{X}_{i t}$ is a vector of baseline controls. We parametrically control for the smooth relationship between rank and applications with $f\left(\operatorname{rank}_{i t}\right)$. As a baseline, we utilize a quartic polynomial but also present results for higher and lower order polynomials. We primarily focus on results that pool IHEs ranked as National Universities with those ranked under Liberal Arts but we present separate results for both ranking categories for completeness. Following previous research, we take the natural log of applications to normalize application size differences across IHEs and for ease of 
interpreting results. We cluster standard errors at the IHE level for all parametric specifications to account for potential serial correlation.

It is likely that our panel context has IHE-specific time-invariant unobservables that would motivate the use of a fixed effects regression in a traditional setting. However, as noted by Lee and Lemieux (2010), including fixed effects is unnecessary for identification in the RD design. Similarly, year fixed effects can be included as a baseline covariate but are not necessary for identification. Furthermore, including IHE fixed effects could actually increase the variance of the RD estimator when there is little within-IHE variation in the treatment status (Lee and Lemiux, 2010). This is precisely the case in the USNWR rankings. For example, few IHE's move in or out of the top 10 from year to year; but, applications are highly persistent from year to year within an IHE, so including lagged applications can help reduce sampling error (Lee and Lemieux, 2010). Therefore, we borrow this intuition from the RD literature and include a lag of logged applications as a baseline control. Our natural experiment can thus be conceptualized as, "Conditional on the previous year's applications, is there a discontinuous change in applications when crossing over a salient rankings threshold?"

Table 3 shows regression results for the pooled sample including National Universities and Liberal Arts institutions using quartic polynomial controls. Column 1 only controls for the lag of logged applications, a quartic polynomial of IHE rank, and the ranking thresholds of 10, 50, and 100. Column 2 adds indicator variables for year, Carnegie classification (Bachelors only vs. offering graduate degrees), and sector (private vs. public IHE). Therefore, we are identifying the discontinuities in column 2 by comparing applications at IHEs of different rankings but in the same Carnegie classification, sector, and year. In columns 3 and 4, we add additional time-varying controls for IHE quality. We lag these variables by one year to reflect the quality of the IHE at the time that students are making their application decisions. Column 3 adds only real instructional expenditures per student and real total expenditures per student whereas column 4 also adds the average of the 75th percentile of an IHE's verbal and math SAT scores. ${ }^{11}$ Finally, column 5 estimates the model including IHE fixed effects. This restricts us to utilizing variation in rankings within the IHE to identify the model. ${ }^{12}$

Table 3. Regression Results: Effects of Rankings Thresholds on Logged Applications.
(1)
(2)
(3)
(4)
(5)

Threshold

$\begin{array}{llllll}>10 & 0.00949 & 0.00389 & 0.00122 & 0.00778 & -0.0238 \\ & (0.0126) & (0.0120) & (0.0122) & (0.0128) & (0.0393) \\ >50 & -0.0196^{*} & -0.0223^{* *} & -0.0221^{* *} & -0.0190^{*} & -0.0430^{* *} \\ & (0.0112) & (0.0109) & (0.0111) & (0.0114) & (0.0218) \\ >100 & -0.0221^{*} & -0.0220^{*} & -0.0208 & -0.0204 & -0.0240 \\ & (0.0128) & (0.0127) & (0.0129) & (0.0140) & (0.0176) \\ \text { Indicators for Carnegie, Sector, Year } & \text { No } & \text { Yes } & \text { Yes } & \text { Yes } & \text { No } \\ \text { IHE Fixed Effects } & \text { No } & \text { No } & \text { No } & \text { No } & \text { Yes } \\ \text { Additional Time-Varying Controls } & \text { None } & \text { None } & \text { Exp./Student Exp./Student, SAT None }\end{array}$


$\begin{array}{lllll}\text { (1) } & \text { (2) } & \text { (3) } & \text { (4) } & \text { (5) }\end{array}$

$\begin{array}{llllll}\text { Observations } & 2613 & 2613 & 2585 & 2371 & 2613 \\ \text { R-squared } & 0.987 & 0.987 & 0.987 & 0.987 & 0.991\end{array}$

Notes: Robust standard errors in parentheses are clustered at the IHE level.

*** $p<0.01, * * p<0.05, * p<0.1$.

Regression specifications for all columns include the one-year lag of logged applications and quartic polynomials of USNWR rank. Exp./Student indicates controls for 1-year lags of instructional and total expenditures per student. SAT indicates controls for the 1-year lag of the average of the 75th percentile of verbal and math SAT scores.

As seen in Table 3, the most robust discontinuity occurs at the threshold of 50 . We find an approximate $2 \%$ drop in applications when an IHE crosses the threshold of 50 . We also see some evidence of a similar discontinuous drop in applications as an IHE crosses the threshold of 100 in the rankings where the estimates are statistically significant at the $10 \%$ level in columns 1 and 2 . We do not see any evidence of discontinuities in applications at the thresholds of $10 .{ }^{13}$ Table 4 separates our sample into the two USNWR categories of National Universities and Liberal Arts colleges. The magnitude of the drop at the threshold of 50 is slightly larger for Liberal Arts Colleges as compared to National Universities in terms of point estimates. However, the effect is less precisely estimated for Liberal Arts IHEs.

Table 4. Regression Results by USNWR Category: Effects of Rankings Thresholds on Logged Applications.

National Universities Liberal Arts
$\begin{array}{lll}\text { (1) (2) } & \text { (3) (4) }\end{array}$

Threshold

\begin{tabular}{|c|c|c|c|c|}
\hline \multirow[t]{2}{*}{$>10$} & 0.00358 & 0.00369 & 0.0143 & 0.0266 \\
\hline & $(0.0172)$ & $(0.0183)$ & $(0.0150)$ & (0.0166) \\
\hline \multirow[t]{2}{*}{$>50$} & $-0.0195^{*}$ & $-0.0190^{*}$ & $-0.0339^{*}$ & -0.0322 \\
\hline & (0.00998 & (0.0103) & $(0.0189)$ & (0.0210) \\
\hline \multirow[t]{2}{*}{$>100$} & -0.0245 & -0.0257 & -0.0123 & -0.00287 \\
\hline & $(0.0153)$ & $(0.0162)$ & $(0.0213)$ & $(0.0236)$ \\
\hline
\end{tabular}

Additional Time-Varying Controls No

Exp./Student, SAT No

Exp./Student, SAT

Observations

$1368 \quad 1294$

$1245 \quad 1077$

R-squared

$0.981 \quad 0.980$

0.960

0.961

Notes: Robust standard errors in parentheses are clustered at the IHE level.

Regression specifications for all columns include the one-year lag of logged applications, quartic polynomials of USNWR rank, and indicators for Carnegie classification, IHE sector, and year.

*** $p<0.01, * * p<0.05, * p<0.1$.

Exp./Student indicates controls for 1-year lags of instructional and total expenditures per student.

SAT indicates controls for the 1-year lag of the average of the 75th percentile of verbal and math SAT scores. 
One concern is that our results could be driven by the specific polynomial controls that we have chosen to capture the smooth relationship between ranking and applications. Therefore, we present results for the pooled sample in Appendix Table A1 using polynomials of order 2, 3, 5, 6, and 7. As seen in Table A1, the discontinuity in crossing the ranking threshold of 50 is robust to the choice of polynomial. Also, we consistently see negative point estimates when crossing the threshold of 100 but most of the estimates are statistically insignificant. To provide more insight into the magnitudes of the effects, we present results using the level of applications in place of logged applications in Table 5. On average, IHEs lose several hundred applications when falling out of the top 50. Coefficients on the indicators for the ranking threshold of 100 are consistently negative across the specifications in Table 5, but typically are not precisely estimated.

Table 5. Regression Results: Effects of Rankings Thresholds on Level of Applications.
(1)
(2)
(3)
(4)
(5)
(6)

Threshold

\begin{tabular}{lllllll}
$>10$ & -207.1 & -81.13 & 58.47 & 69.49 & 32.56 & -16.96 \\
& $(127.5)$ & $(156.0)$ & $(170.2)$ & $(196.1)$ & $(206.6)$ & $(199.4)$ \\
$>50$ & $-198.6^{*}$ & $-190.2^{*}$ & $-264.4^{* *}$ & $-270.6^{* *}$ & $-266.7^{*}$ & $-386.9^{* *}$ \\
& $(112.7)$ & $(111.8)$ & $(118.4)$ & $(137.4)$ & $(137.3)$ & $(153.7)$ \\
$>100$ & -106.2 & $-200.3^{*}$ & -174.6 & -169.0 & -155.8 & -39.42 \\
& $(87.00)$ & $(106.4)$ & $(107.1)$ & $(116.0)$ & $(116.4)$ & $(127.9)$ \\
\multirow{2}{*}{ Polynomial Order } & 2 & 3 & 4 & 5 & 6 & 7 \\
Observations & 2613 & 2613 & 2613 & 2613 & 2613 & 2613 \\
R-squared & 0.984 & 0.984 & 0.984 & 0.984 & 0.984 & 0.984
\end{tabular}

Notes: Robust standard errors in parentheses are clustered at the IHE level.

$* * * \mathrm{p}<0.01, * * \mathrm{p}<0.05, * \mathrm{p}<0.1$.

Regression specifications for all columns include the 1-year lag of applications, indicators for Carnegie classification, IHE sector, and year.

Our results indicate that the rankings threshold of 50 is the most important cutoff in determining applications. Crossing over 50 is the only ranking where we see robust evidence of a significant discontinuity; there is little to no evidence of a discontinuity when dropping out of the top 10 and only weak evidence that dropping out of the top 100 discontinuously affects applications. One plausible explanation is that the thresholds of 10 and 100 are not as salient to students because these do not correspond to page breaks in the printed USNWR guides. Another potential factor is that there is not much variation in IHEs that cross over the threshold of 10. For the years 2005-2013 there are only 2 (6) instances where a National University (Liberal Arts IHE) moves into the top 10. Similarly, there are only 3 (5) occasions where a National University (Liberal Arts IHE) falls out of the top 10.

Thus far, we have included all observations in our analysis to identify potential discontinuities. The benefit of this approach is that we can simultaneously estimate effects at multiple thresholds. However, the downside is that we are identifying effects in part using data far from the thresholds of 
interest. For example, it may be undesirable to identify a discontinuity at the threshold of 50 with observations from IHEs ranked in the top 10 or worse than 100 . Therefore, rather than fitting all the data with a parametric function, we next focus on the most important threshold of 50 and conduct a more data-driven analysis.

\subsection{Nonparametric local linear RD}

In our application, the running variable of USNWR ranking determines assignment to the limited visibility treatment. IHEs ranked at 50 or better always appear on the first page of the printed USNWR guide whereas IHEs ranked at 51 or worse always appear on the second or third page of the guide. We first present some graphical evidence of a discontinuity in applications at this threshold. Fig. 3 shows a RD plot for applications to National Universities and Fig. 4 shows the analogous plot for Liberal Arts Colleges. Both of these figures plot the raw applications data and fit quadratic polynomials to both sides of the 50-threshold. There are sizable discontinuities in both figures with the drop in applications especially noticeable for Liberal Arts Colleges in Fig. 4. For National Universities, there is a graphical discontinuity of approximately 4000 applications when crossing the 50-threshold. Relative to average applications of approximately 24,000 for National Universities ranked between 40 and 60, this represents an approximate $17 \%$ discontinuous drop. The analogous graphical drop for Liberal Arts Colleges is approximately 1300 applications. This represents an approximate $34 \%$ discontinuous drop at the threshold of 50 relative to average applications for Liberal Arts Colleges ranked between 40 and 60 . However, the graphical evidence from the raw data likely overstates the magnitude of the discontinuity because applications and rankings tend to be persistent over time. We therefore continue to the RD regressions, which condition on some observable characteristics including the lag of logged applications.

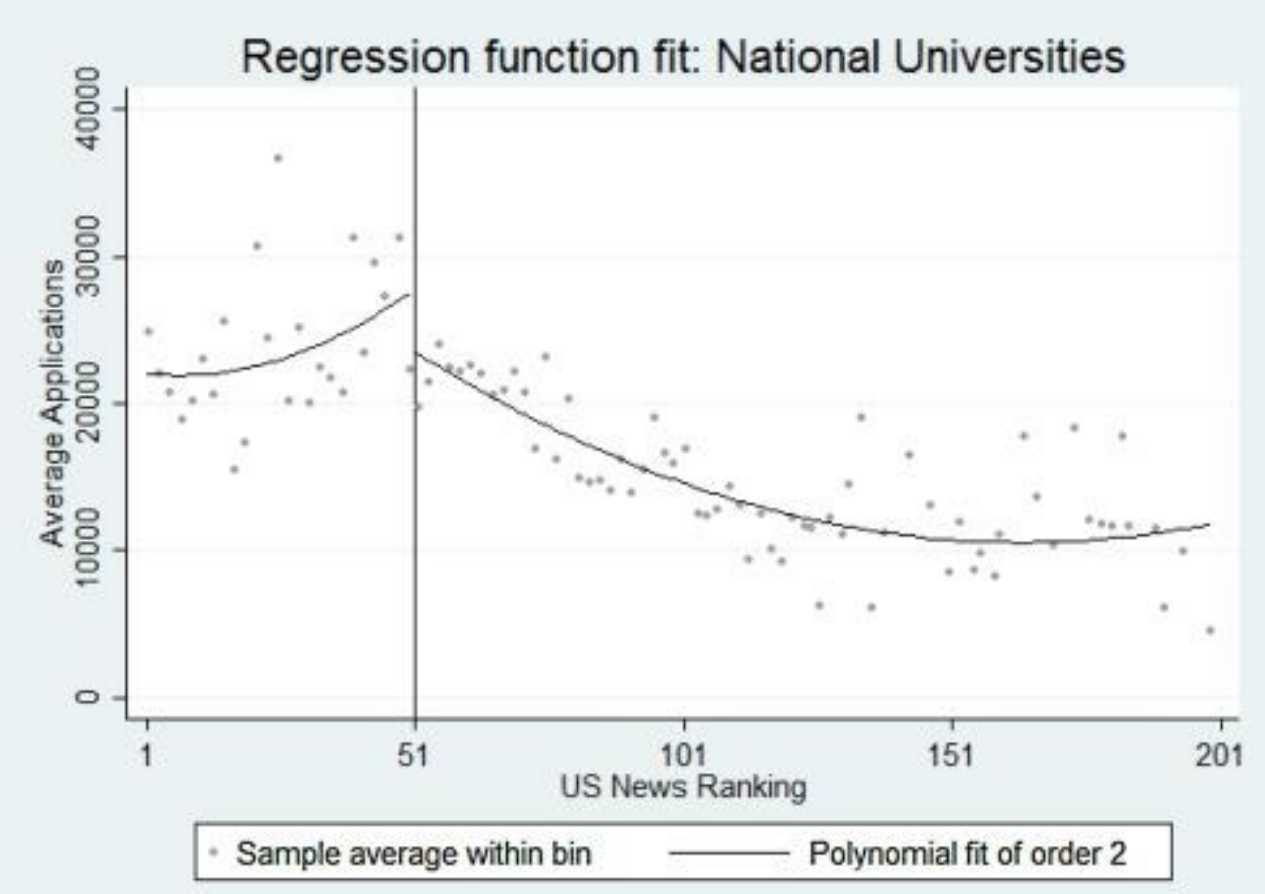

Fig. 3. RD Plot for National Universities. 
Notes: This figure shows average applications by USNWR Ranking for all IHEs in the National University classification. The vertical line indicates the RD cutoff. Global quadratic functions are fit on both sides of the RD cutoff. The graph is produced using rdplot within the rdrobust package in Stata (Calonico et al., 2016c).

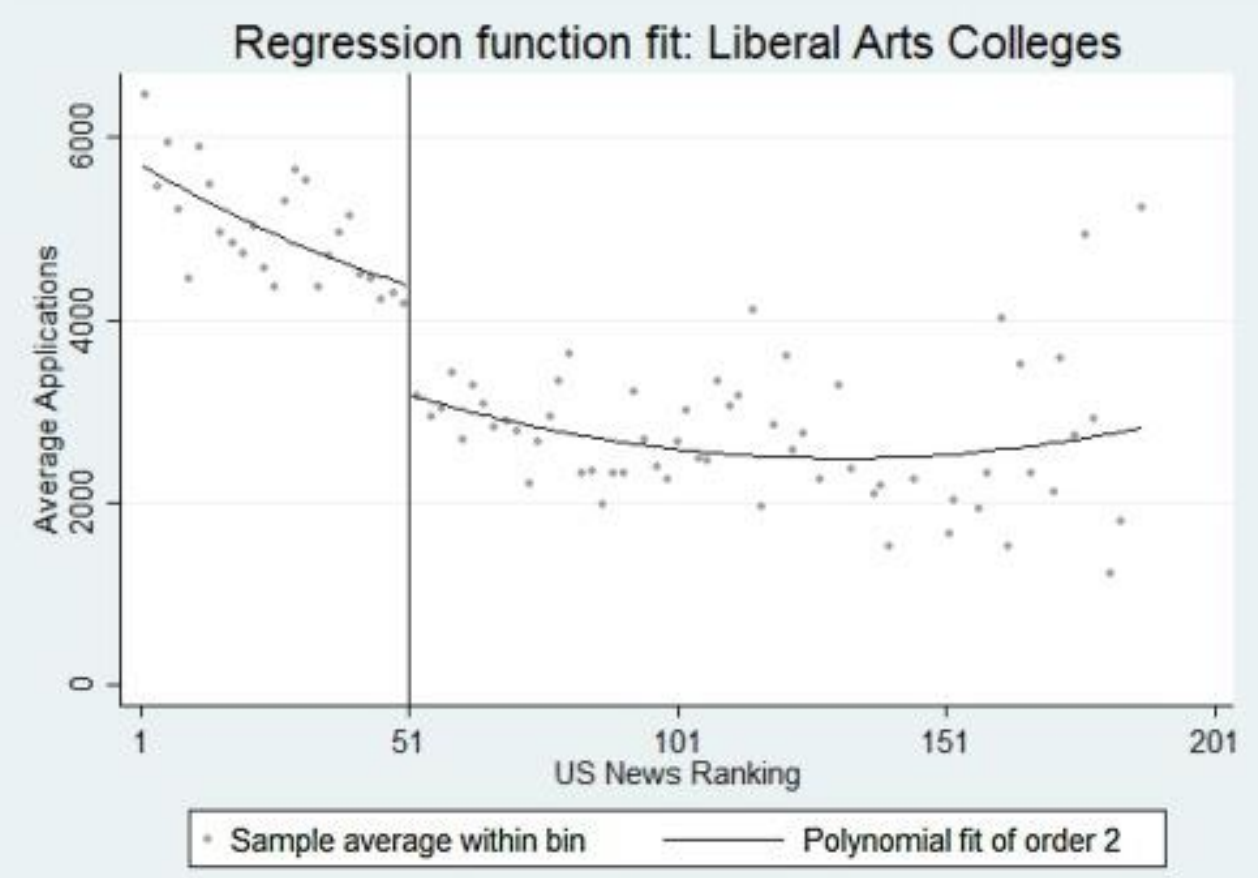

Fig. 4. RD Plot for Liberal Arts Colleges.

Notes: This figure shows average applications by USNWR Ranking for all IHEs in the National University classification. The vertical line indicates the RD cutoff. Global quadratic functions are fit on both sides of the RD cutoff. The graph is produced using rdplot within the rdrobust package in Stata (Calonico et al., 2016c).

For our RD analysis, we normalize the USNWR rank by the threshold value with

$\overline{\operatorname{rank}}_{i t}=\operatorname{rank}_{i t}-51$

This results in the basic RD specification

$\operatorname{lnapp}_{i t}=\alpha+f\left(\widetilde{\operatorname{rank}}_{i t}\right)+\beta * I\left(\operatorname{rank}_{i t}>50\right)+\gamma X_{i t}+\varepsilon_{i t}$,

where $f($.$) controls for the underlying relationship between USNWR ranking and applications, { }^{14} I($.$) is the$ indicator function, and $\boldsymbol{X}_{i t}$ includes a vector of predetermined IHE covariates. As in the parametric analysis of Section 3.1, we include a lag of the dependent variable in $\boldsymbol{X}_{\boldsymbol{i t}}$ to reduce the variance of our estimates. $B$ is the parameter of interest, representing the limited attention treatment effect.

RD estimators are often constructed with local polynomial non-parametric regression, where the local linear RD estimator is "perhaps the preferred and most common choice in practice" (Calonico et al., 2014b). ${ }^{15}$ The benefit of narrowing the bandwidth for the RD is that we are less concerned about the adequacy of the polynomial controls but this comes at a cost of losing some information. One criterion 
for the choice of the bandwidth for this local estimator is to find the bandwidth that minimizes MSE of the local linear RD estimator ${ }^{16}$ (Imbens and Kalyanaraman, 2012). Calonico et al. (2014a) build on Imbens and Kalyanaraman (2012) to construct another MSE-optimal bandwidth selector and Calonico et al. (2016b) extends this to allow covariates. We present results utilizing the Calonico et al. (2016b) MSE optimal bandwidth selector as well the coverage error rate (CER) optimal bandwidth selector developed in Calonico et al., 2016a, Calonico et al., 2016b.

Conventional RD point estimation in practice often ignores bias by either assuming that it is small or by shrinking the bandwidth enough so that the bias should disappear (Calonico et al., 2014a, Calonico et al., 2014b). However, a second approach is to construct an estimate of the bias and subtract that from the point estimate of the treatment effect. The key insight of Calonico et al. (2014a) is that inference should also account for the bias term in the estimated effects rather than rely on large-sample approximations. Therefore, we utilize a local linear RD point estimator with inference from robust nonparametric bias-correction methods (Calonico et al., 2014a, Calonico et al., 2014b, Calonico et al., 2016a, Calonico et al., 2016b, Calonico et al., 2016c). ${ }^{17}$ We use the lag of logged applications, year fixed effects, a dummy for private versus public IHE, and a dummy for Carnegie classification of a bachelors institution as baseline covariates to improve precision. We report results using both the robust nearest neighbor variance estimation of Calonico et al., 2014a, Calonico et al., 2014b and the cluster robust nearest neighbor variance estimator as implemented in Calonico et al., 2016b, Calonico et al., 2016c. ${ }^{18}$ As is standard in the RD literature, we primarily utilize a triangular kernel, which weights observations closer to the RD cutoff more heavily. We also present results using a uniform kernel to display the robustness of the results.

Table 6 shows the local linear RD results at the threshold of 50. For completeness, we show conventional, bias-corrected (with conventional inference), and robust estimates of the RD treatment effect. The first four columns use a MSE-optimal bandwidth selector and last two columns use a CERoptimal bandwidth selector. These two bandwidth selectors are suggested by Calonico et al., 2016a, Calonico et al., 2016b, Calonico et al., 2016c. Specifications in columns 3 and 4 add additional timevarying controls for IHE quality; all others in Table 6 use only the aforementioned baseline covariates. Focusing on the bias-corrected point estimates, we see that crossing the ranking threshold of 50 results in an approximate $4.5 \%-6 \%$ drop in applications. Moreover, the results are statistically significant across all specifications in Table 6 and persist when using robust variance estimators in place of conventional inference procedures.

Table 6. Local Linear RD Results at Ranking Threshold of 50 with Optimal Bandwidths.

(1)

Conventional

Bias-Corrected

Bias-Corrected Robust
(2) (3) (4)

$\begin{array}{lll}-0.0434^{* *}-0.0458^{* *}-0.0459^{* *} & -0.0409^{* *} \\ (0.0218) & (0.0192) & (0.0194)\end{array}$$$
-0.0492^{* *}-0.0512^{* * *}-0.0515^{* * *}-0.0458^{* *}
$$$$
\text { (0.0218) (0.0192) (0.0194) }
$$$$
-0.0492^{*}-0.0512^{* *}-0.0515^{* *}
$$

(0.0260) (0.0226)

(0.0228)
(0.0200)

$-0.0458^{*}$

(0.0238)
(5)

(6) $-0.0567^{*}-0.0560^{* *}$ (0.0293) (0.0237) $-0.0595^{* *}-0.0592^{* *}$ (0.0293) (0.0237) $-0.0595^{*}-0.0592^{* *}$ (0.0314) (0.0258) 


\begin{tabular}{|c|c|c|c|c|c|c|}
\hline & (1) & (2) & (3) & (4) & (5) & (6) \\
\hline BW Selection & MSE & MSE & MSE & MSE & CER & CER \\
\hline Order Local Poly & 1 & 1 & 1 & 1 & 1 & 1 \\
\hline Order Bias & 2 & 2 & 2 & 2 & 2 & 2 \\
\hline BW Local Poly & 17.20 & 15.91 & 15.76 & 15.63 & 11.61 & 11.76 \\
\hline BW Bias & 29.19 & 27.74 & 27.59 & 26.99 & 29.19 & 27.74 \\
\hline $\begin{array}{l}\text { Variance Estimator for Robust } \\
\text { Inference }\end{array}$ & NN & $\begin{array}{l}\text { NN } \\
\text { cluster }\end{array}$ & NN cluster & NN cluster & NN & $\begin{array}{l}\text { NN } \\
\text { cluster }\end{array}$ \\
\hline Effective Observations & 664 & 570 & 558 & 503 & 441 & 441 \\
\hline Additional Time-Varying Controls & & & Exp./Stud & $\begin{array}{l}\text { Exp./Studer } \\
\text { SAT }\end{array}$ & & \\
\hline
\end{tabular}

Notes: Triangular kernel used in all columns.

Standard errors in parentheses. BW = bandwidth, MSE = MSE-optimal, CER = CER-optimal.

Standard errors in columns 2, 3, 4, and 6 are clustered at the IHE level.

$\mathrm{NN}$ indicates heteroskedasticity-robust nearest neighbor variance estimator.

NN cluster indicates cluster-robust nearest neighbor variance estimator clustered at the IHE level.

Exp./Student indicates controls for 1-year lags of instructional and total expenditures per student. SAT indicates controls for the 1-year lag of the average of the 75th percentile of verbal and math SAT scores.

We also manually set the bandwidth to 20,30 , and 40 rankings on either side of our threshold in Appendix Table A2. The bandwidth of 40 results in the largest possible bandwidth without crossing over another potentially important threshold (at a ranking of 10). Point estimates remain in the range of $-4 \%$ to $-6 \%$ across these bandwidths and estimates remain statistically significant. We also show results from local linear regressions using a uniform kernel in Appendix Table A3 and from local quadratic regressions in Appendix Table A4. Results are robust to these alternative specifications. ${ }^{19}$

Table 7 shows RD results when we split the sample according to USNWR classification. We initially set the bandwidth at 40 for these subsamples to include a larger number of observations but also show results with a narrower bandwidth of 20. The outside-top-50 treatment effect is stronger for Liberal Arts Colleges than for National Universities. One explanation for this is that over one-half of the IHEs in the National Universities category are public whereas all but 36 observations from Liberal Arts Colleges are private IHEs. Students applying to public universities are typically more price sensitive (Leslie and Brinkman, 1987, Heller, 1997), and some proportion of them are paying discounted in-state tuition, so rankings may play a smaller role in the National University category.

Table 7. Local Linear RD Results by Classification.

\section{National Universities (1-4)}

Conventiona I
(1)

(2)

(3) (4)

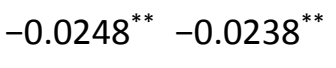

$(0.0117) \quad(0.0118)$
$-0.0294-0.0288$

(0.0191) (0.0195)
Liberal Arts Colleges (5-8)

(5) (6)

(7)

(8)

$\begin{array}{cccc}-0.0308^{* *} & -0.0245 & -0.0498^{* *} & -0.0441^{* *} \\ (0.0154) & (0.0165) & (0.0220) & (0.0221)\end{array}$


National Universities (1-4)

(1) (2) (3)

(3) (4)

(4) (5)

Liberal Arts Colleges (5-8)

\begin{tabular}{|c|c|c|c|c|c|c|c|c|}
\hline \multirow[t]{2}{*}{$\begin{array}{l}\text { Bias- } \\
\text { Corrected }\end{array}$} & $\begin{array}{l}-0.0319^{* *} \\
*\end{array}$ & $-0.0294^{* *}$ & $\begin{array}{l}-0.0348 \\
*\end{array}$ & $-0.0344^{*}$ & $\begin{array}{l}-0.0533^{*} \\
*\end{array}$ & $-0.0481^{* * *}$ & $\begin{array}{l}-0.0858^{*} \\
*\end{array}$ & $-0.0743^{* * *}$ \\
\hline & $(0.0117)$ & (0.0118) & (0.0191) & (0.0195) & $(0.0154)$ & $(0.0165)$ & $(0.0220)$ & $(0.0221)$ \\
\hline
\end{tabular}

Bias-

\begin{tabular}{|c|c|c|c|c|c|c|c|c|}
\hline $\begin{array}{l}\text { Corrected } \\
\text { Robust }\end{array}$ & -0.0319 & -0.0293 & -0.0348 & -0.0344 & $-0.0533^{* *}$ & $-0.0481^{* *}$ & $-0.0858^{* *}$ & $-0.0743^{* *}$ \\
\hline & (0.0199) & $(0.0199)$ & $(0.0359)$ & $(0.0364)$ & $(0.0234)$ & $(0.0236)$ & $(0.0351)$ & $(0.0376)$ \\
\hline $\begin{array}{l}\text { BW } \\
\text { Selection }\end{array}$ & Manual & Manual & Manual & Manual & Manual & Manual & Manual & Manual \\
\hline $\begin{array}{l}\text { Order Local } \\
\text { Poly }\end{array}$ & 1 & 1 & 1 & 1 & 1 & 1 & 1 & 1 \\
\hline Order Bias & 2 & 2 & 2 & 2 & 2 & 2 & 2 & 2 \\
\hline $\begin{array}{l}\text { BW Local } \\
\text { Poly }\end{array}$ & 40 & 40 & 20 & 20 & 40 & 40 & 20 & 20 \\
\hline BW Bias & 40 & 40 & 20 & 20 & 40 & 40 & 20 & 20 \\
\hline Effective & & & & & & & & \\
\hline $\begin{array}{l}\text { Observation } \\
\mathrm{s}\end{array}$ & 762 & 732 & 363 & 345 & 742 & 630 & 384 & 317 \\
\hline Additional & & & & & & & & \\
\hline $\begin{array}{l}\text { Time- } \\
\text { Varying }\end{array}$ & & $\begin{array}{l}\text { Exp./Student } \\
\text {, SAT }\end{array}$ & & $\begin{array}{l}\text { Exp./Student } \\
\text {, SAT }\end{array}$ & & $\begin{array}{l}\text { Exp./Student } \\
\text {, SAT }\end{array}$ & & $\begin{array}{l}\text { Exp./Student } \\
\text {, SAT }\end{array}$ \\
\hline
\end{tabular}

Notes: Triangular kernel used in all columns.

Standard errors in parentheses are clustered at the IHE level. BW=bandwidth.

Cluster-robust nearest neighbor variance estimator, clustered at the IHE level, is used for "Bias-Corrected Robust" standard errors in all columns.

Exp./Student indicates controls for 1-year lags of instructional and total expenditures per student.

SAT indicates controls for the 1-year lag of the average of the 75th percentile of verbal and math SAT scores.

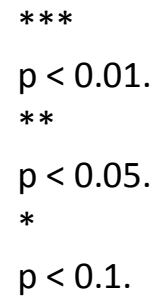

We also note that we conducted the analogous analysis at the rankings threshold of 100 . We find point estimates of $-2 \%$ to $-3 \%$ across all specifications for crossing the threshold of 100 but estimates on the pooled data are never statistically significant at conventional levels. The estimated effect is again stronger for Liberal Arts Colleges than for National Universities at the 100-threshold, where we find a bias-corrected point estimate for Liberal Arts Colleges in the range of $-4 \%$ to $-5 \%$, statistically 
significant at the $10 \%$ level for some bandwidths. The bias-corrected point estimate for National Universities is in the range of $-1 \%$ to $-1.5 \%$ with standard errors that are twice as large. Thus, we conclude that there is only weak evidence of limited attention at the 100-threshold.

\subsection{Validity checks and falsification tests}

It is important to conduct various validity checks when using a RD design (Lee and Lemieux, 2010). First, we verify that the included baseline covariates have equal conditional expectations at the RD cutoff. That is, we check for a discontinuity in the lag of logged applications at the ranking threshold of 50. A discontinuity in this baseline covariate could cause our RD treatment effect estimator of interest to be inconsistent. As seen in columns 1 and 2 of Table 8, we do not find any statistically significant RD treatment effects for this baseline covariate. ${ }^{20}$ We also test for a discontinuous change in real tuition at the ranking threshold of 50 in columns 3 and 4 of Table 8. We do not find any evidence for a discontinuous change in real tuition, effectively ruling this out as an alternative explanation of our results.

Table 8. Local Linear RD Validity Checks.

\begin{tabular}{|c|c|c|c|c|c|c|}
\hline \multirow[t]{2}{*}{ Outcome } & \multicolumn{4}{|c|}{ Lag of Logged Applications Real Tuition } & \multicolumn{2}{|c|}{ Overall Composite Score } \\
\hline & (1) & (2) & (3) & (4) & (5) & (6) \\
\hline \multirow[t]{2}{*}{ Conventional } & -0.0479 & -0.0205 & -0.0777 & -0.572 & -0.353 & -0.143 \\
\hline & $(0.195)$ & $(0.208)$ & $(1.38)$ & $(1.44)$ & $(1.56)$ & $(1.65)$ \\
\hline \multirow[t]{2}{*}{ Bias-Corrected } & -0.0315 & -0.0111 & -0.508 & -0.795 & -0.462 & -0.218 \\
\hline & $(0.195)$ & $(0.208)$ & $(1.38)$ & $(1.44)$ & $(1.56)$ & $(1.65)$ \\
\hline \multirow[t]{2}{*}{ Bias-Corrected Robust } & -0.0315 & -0.0111 & -0.508 & -0.795 & -0.462 & -0.218 \\
\hline & $(0.230)$ & $(0.228)$ & $(1.60)$ & $(1.57)$ & $(1.79)$ & $(1.81)$ \\
\hline BW Selection & MSE & CER & MSE & CER & MSE & CER \\
\hline Order Local Poly & 1 & 1 & 1 & 1 & 1 & 1 \\
\hline Order Bias & 2 & 2 & 2 & 2 & 2 & 2 \\
\hline BW Local Poly & 21.66 & 16.02 & 21.43 & 15.85 & 19.74 & 14.59 \\
\hline BW Bias & 30.67 & 30.67 & 30.46 & 30.46 & 27.87 & 27.87 \\
\hline Effective Observations & 839 & 616 & 849 & 579 & 769 & 552 \\
\hline
\end{tabular}

Notes: Triangular kernel used in all columns.

Standard errors in parentheses are clustered at the IHE level. BW $=$ bandwidth, MSE $=$ MSE-optimal, CER $=$ CERoptimal.

Cluster-robust nearest neighbor variance estimator, clustered at the IHE level, is used for "Bias-Corrected Robust" standard errors in all columns.

$* * * p<0.01, * * p<0.05, * p<0.1$.

Another typical RD validity check is to look for possible manipulation in the assignment of the running variable to treatment status. This is typically done by testing for a discontinuity in the density of observations at the RD cutoff. In theory, it should not be possible to have such a discontinuity in our context because the running variable, USNWR ranking, is ordinal. Concentrating on the top 100 IHES 
for example, there should be a uniform distribution of rankings. In practice, there are often ties in rankings so we observe specific values more frequently than others. We therefore conduct a formal test for a discontinuity in the density of observations at the cutoff of 50 and find no evidence of RD manipulation (robust $p$-value $=0.90) .^{21}$

Our explanation for the discontinuous drop in applications at the threshold of 50 is that students are displaying limited attention to the numerical ranking and placing undue importance on whether an IHE lands in the top-50. However, it could also be that there is truly a discontinuous drop in IHE quality at the threshold of 50. A feature of the USNWR rankings helps us test for a discontinuity in IHE quality. Along with the ordinal ranking, there is also a numerical "overall score" printed in the guide. Specifically, the overall score is a weighted composite of underlying quality indicators. The USNWR states that the indicators and weights for 2017 are as follows (with weights in parentheses): graduation and retention rates (22.5\%), undergraduate academic reputation (22.5\%), faculty resources (20\%), student selectivity (12.5\%), financial resources (10\%), graduation rate performance $(7.5 \%)$, and alumni giving rate (5\%). Then, "the final scores were rescaled so that the top school in each category received a value of 100 , and the other schools' weighted scores were calculated as a proportion of that top score." USNWR rounds the composite score to the nearest whole number and then creates the ordinal rankings from the overall composite score. Therefore, while not a perfect measure of IHE quality, the overall composite score does carry some cardinal information.

A sensible test for a discontinuous drop in IHE quality at the threshold of 50 is to use this overall composite score as a dependent variable and estimate the RD treatment effect at the ranking of 50. Fig. 5 shows a RD plot of ranking (with a bin width of 2) versus the average overall composite score. Visually, it appears that there is a continuous relationship between ranking and overall composite score in the neighborhood of the ranking threshold of 50. More formally, we utilize nonparametric local linear regression with overall composite score as the outcome variable; these results appear in columns 5 and 6 of Table 8. We find no statistical evidence of a discontinuity in IHE quality at the threshold of 50 . 


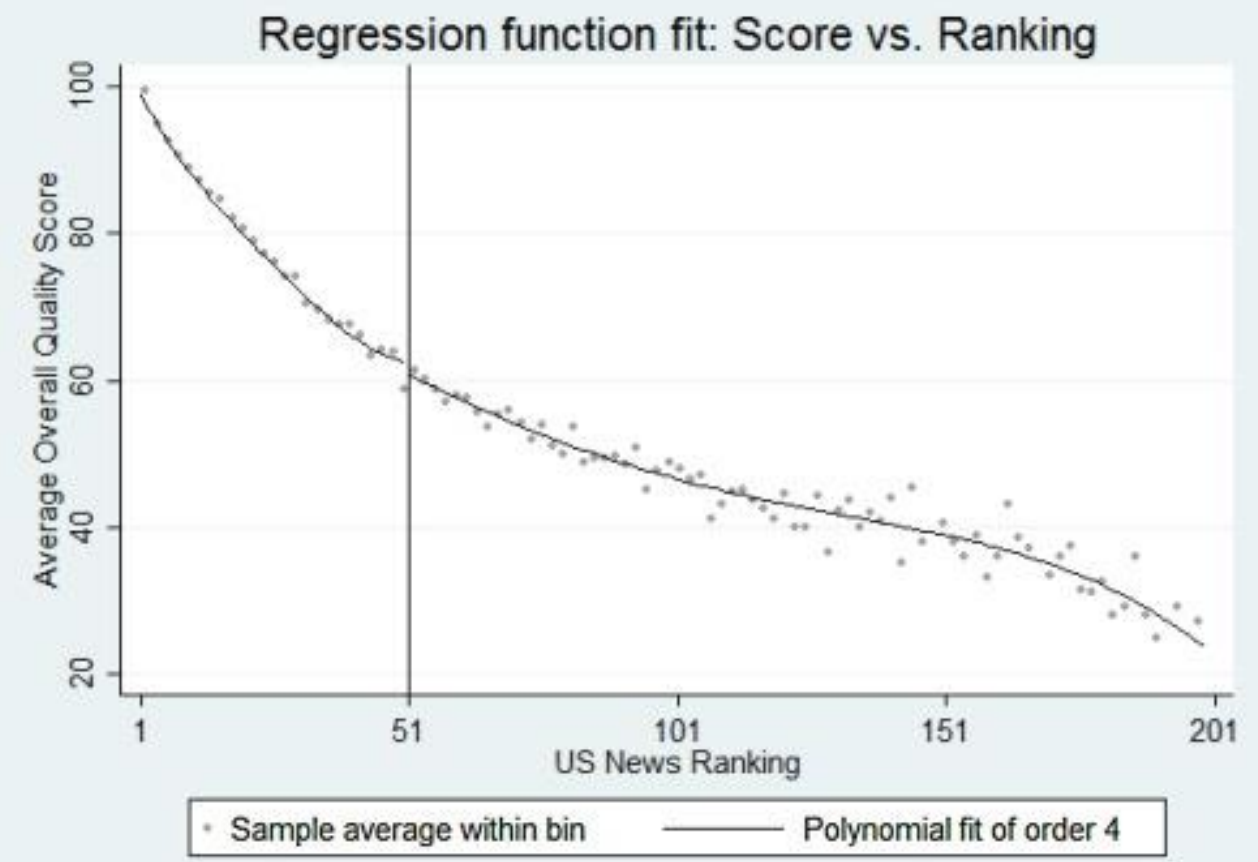

Fig. 5. Overall Score vs. Rank.

Notes: This figure shows average overall composite score by USNWR Ranking for all IHEs in the estimation sample. The vertical line indicates the RD cutoff. Global quartic functions are fit on both sides of the RD cutoff. The graph is produced using rdplot within the rdrobust package in Stata (Calonico et al., 2016c).

We also investigate several falsification tests where we look for discontinuities in applications at rankings thresholds that should not matter. The MSE-optimal bandwidth from Table 6 is approximately 15. Thus, we counterfactually move the threshold approximately 15 ranks in both directions and test for discontinuities at the ranks of 35 and 65 . We manually set the bandwidth so as to not include observations at the threshold of 50. Table 9 reports results from these falsification tests; there is no evidence of discontinuities in logged applications at these thresholds. Likewise, we look for discontinuities at the rankings of 25 and 75 which allows us to set the bandwidth as large as possible without crossing over 50/51 or 100/101. Once again, we see no evidence of discontinuities in applications at any of these counterfactual thresholds.

Table 9. Local Linear RD Falsification Tests.

$\begin{array}{lllll} & (1) & (2) & \mathbf{( 3 )} & \mathbf{( 4 )} \\ \text { Threshold } & \mathbf{3 5} & \mathbf{6 5} & \mathbf{2 5} & \mathbf{7 5} \\ \text { Conventional } & 0.0122 & -0.0180 & -0.00549 & 0.00413 \\ & (0.0146) & (0.0195) & (0.0079) & (0.0167) \\ \text { Bias-Corrected } & 0.00098 & -0.0177 & 0.00426 & 0.0146 \\ & (0.0146) & (0.0195) & (0.0079) & (0.0167) \\ \text { Robust } & 0.00098 & -0.0177 & 0.00426 & 0.0146 \\ & (0.0214) & (0.0287) & (0.0114) & (0.0251)\end{array}$




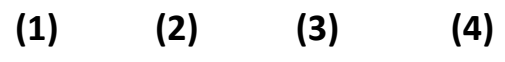

$\begin{array}{lllll}\text { Threshold } & \mathbf{3 5} & \mathbf{6 5} & \mathbf{2 5} & \mathbf{7 5} \\ \text { BW Selection } & \text { Manual } & \text { Manual } & \text { Manual } & \text { Manual } \\ \text { Order Local Poly } & 1 & 1 & 1 & 1 \\ \text { Order Bias } & 2 & 2 & 2 & 2 \\ \text { BW Local Poly } & 15 & 14 & 25 & 24 \\ \text { BW Bias } & 15 & 14 & 25 & 24 \\ \text { Effective Observations } & 543 & 533 & 899 & 936\end{array}$

Notes: Triangular kernel used in all columns.

Standard errors in parentheses are clustered at the IHE level. BW = bandwidth, MSE = MSE-optimal, CER $=$ CERoptimal.

Cluster-robust nearest neighbor variance estimator, clustered at the IHE level, is used for "Bias-Corrected Robust" standard errors in all columns.

${ }^{* * *} \mathrm{p}<0.01, * * \mathrm{p}<0.05, * \mathrm{p}<0.1$.

Finally, one may question the relevance of a physical page break in a printed guide when the internet is increasingly the first place people look for information. Annual reports from the Cooperative Institutional Research Program provide suggestive evidence that magazine rankings have remained relevant over time. Released each year, these reports summarize surveys of several hundred-thousand first-time, full-time, first-year students at several hundred four-year colleges and universities across the United States. ${ }^{22}$ One survey question lists approximately 20 factors that could influence the choice of where to attend college. Among the potential reasons for the choice of a particular college are "Rankings in national magazines" and "Information from a website." Respondents select "very important," "somewhat important," or "not important" for each potential reason. Fig. 6 shows the percentage of students who have selected "very important" for "Rankings in national magazines" and "Information from a website" over the sample period. The percentage of students saying, "Rankings in national magazines" were "very important" remained relatively constant over the sample period, with perhaps a slight increase over time. For comparison, the percentage of students saying "Information from a website" was "very important" increased more substantially over the time period and, beginning in 2008, is slightly higher than the percentage selecting "very important" for "Rankings in national magazines." 


\section{Factor "Very Important" in Choice of a Particular College}

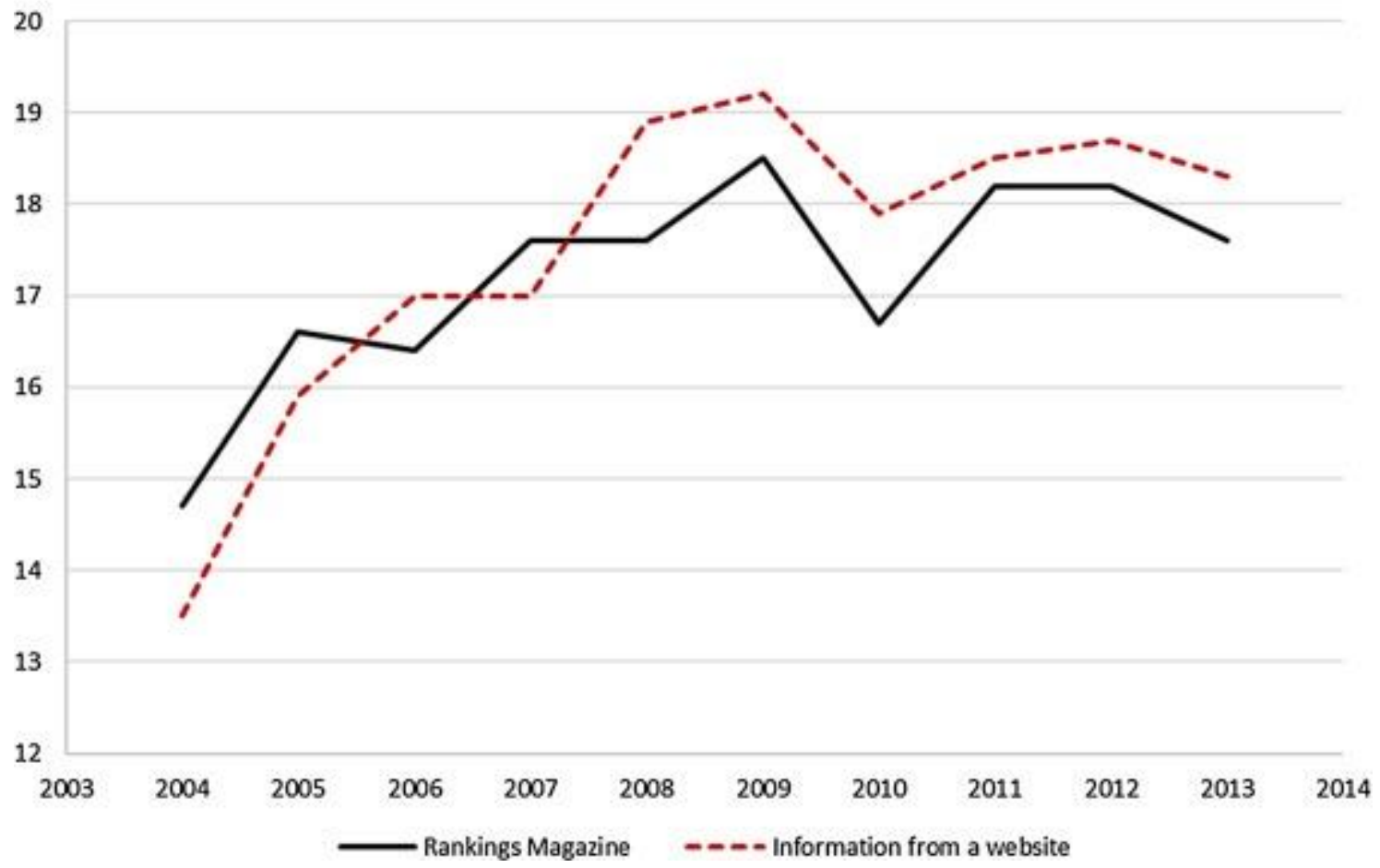

Fig. 6. Cooperative Institutional Research Program Survey Responses over Time.

Notes: This figure shows the percentage of first-time, full-time, first-year students indicating "Rankings in national magazines" and "Information from a website" were "very important" in their choice of a particular college. Data for this figure come from the Cooperative Institutional Research Program's 2004-2013 annual publications on the survey titled "The American Freshman: National Norms."

Other evidence on the changing importance of the print rankings comes from Google Trends. Fig. 7 displays Google search trends for "us news college rankings" and "college application". ${ }^{23}$ Both series are trending up over time and highly seasonal with spikes corresponding to the traditional fall application season. It does appear that, beginning around 2009, the popularity of "us news college rankings" somewhat increases relative to "college application." This suggests that online rankings could have started playing a slightly more prominent role at that time. 


\section{Google Search Popularity}

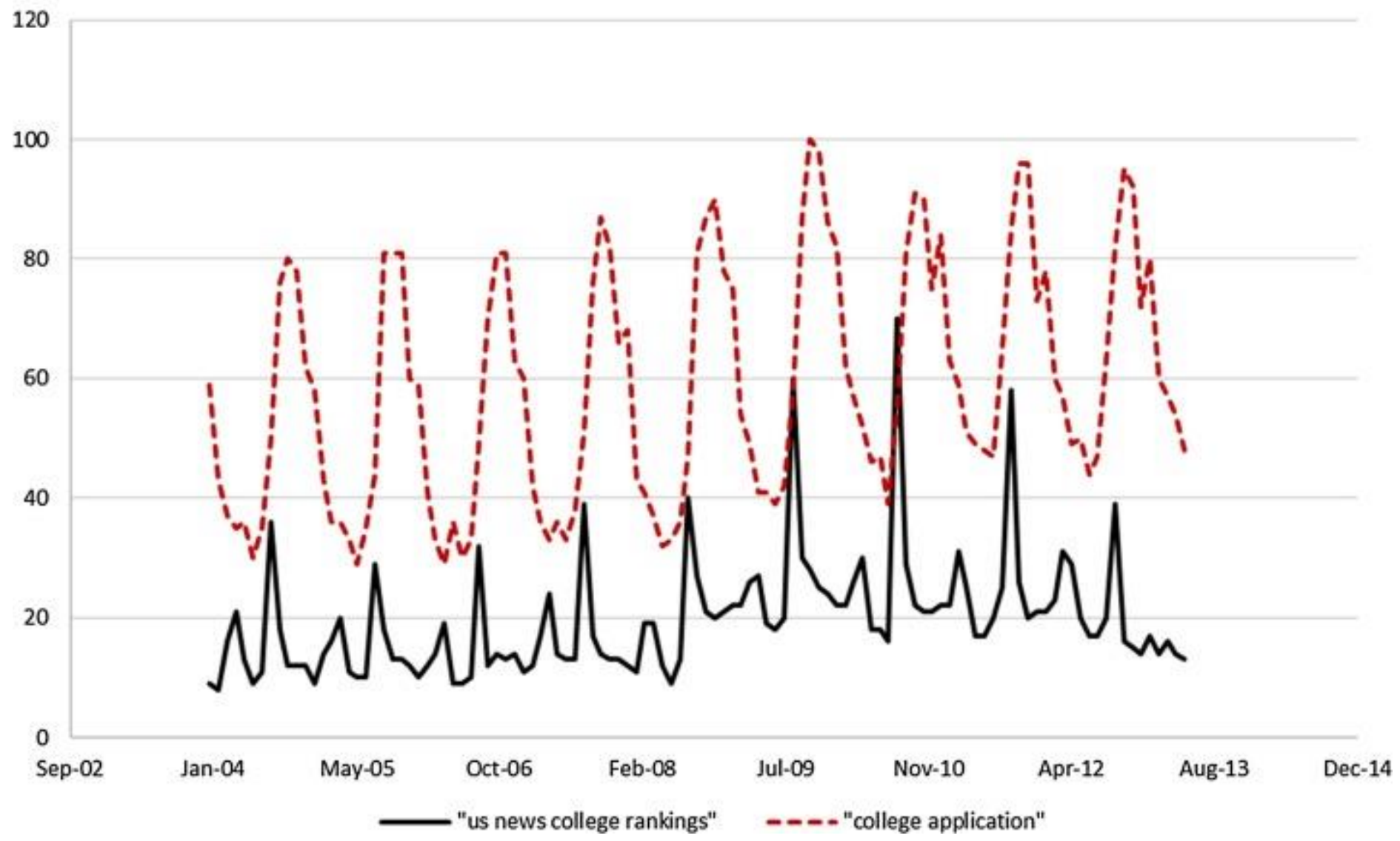

Fig. 7. Google Search Trends for USNWR Rankings over Time.

Notes: This figure shows Google search popularity for the terms "us news college rankings" and "college application." A value of 100 represents peak popularity. Data for this figure come from Google Trends (https://trends.google.com/trends/).

Taken together, the Cooperative Institutional Research Program survey reports and Google trends suggest that we should see a decrease in the importance of the physical page break in the printed guides in the later years of our sample relative to the earlier years. In terms of our analysis, this suggests that the magnitude of the estimated discontinuity in applications at the ranking threshold of 50 should decrease in later years. Table 10 shows RD results when we split our sample into the years of 2004-2008 and 2009-2013. Point estimates of the discontinuity are nearly twice as large for the first five years as compared to the second five years. Furthermore, results are no longer statistically significant at conventional levels when focusing on the period of 2009-2013. This supports our argument that limited attention to the rankings due to a physical break in the printed guide is driving the estimated discontinuity in applications at the ranking threshold of 50 .

Table 10. Local Linear RD Results by Time Period.
(1)
(2)
(3)
(4)

\section{Years}

2004-2008 2004-2008 2009-2013 2009-2013

Conventional

$$
-0.0618 *-0.0776 *-0.0395-0.0461
$$



(1)
(2)
(3)
(4)

\begin{tabular}{lllll} 
Years & \multicolumn{4}{l}{ 2004-2008 2004-2008 2009-2013 2009-2013 } \\
& $(0.0320)$ & $(0.0430)$ & $(0.0260)$ & $(0.0315)$ \\
Bias-Corrected & $-0.0704^{* *}$ & $-0.0828^{*}$ & -0.0413 & -0.0459 \\
& $(0.0320)$ & $(0.0430)$ & $(0.0260)$ & $(0.0315)$ \\
Robust & $-0.0704^{*}$ & $-0.0828^{*}$ & -0.0413 & -0.0459 \\
& $(0.0387)$ & $(0.0469)$ & $(0.0314)$ & $(0.0344)$ \\
BW Selection & MSE & CER & MSE & CER \\
Order Local Poly & 1 & 1 & 1 & 1 \\
Order Bias & 2 & 2 & 2 & 2 \\
BW Local Poly & 17.55 & 13.27 & 13.53 & 10.01 \\
BW Bias & 30.19 & 30.19 & 22.31 & 22.31 \\
Effective Observations & 336 & 252 & 251 & 195
\end{tabular}

Notes: Triangular kernel used in all columns.

Standard errors in parentheses are clustered at the IHE level. BW $=$ bandwidth, MSE $=$ MSE-optimal, CER $=$ CERoptimal.

Cluster-robust nearest neighbor variance estimator, clustered at the IHE level, is used for "Bias-Corrected Robust" standard errors in all columns.

${ }^{* * *} p<0.01,{ }^{* *} p<0.05,{ }^{*} p<0.1$.

\section{Discussion and conclusion}

This paper contributes to the growing body of evidence that economic agents use heuristics to process complex information. We find a discontinuous drop in applications of approximately $5 \%$ when the USNWR rank falls from inside the top 50 to outside the top 50, suggesting that some students are displaying limited attention to rankings. This has implications for long-term student outcomes, as students may be applying to schools that are a worse quality match than they would in absence of limited attention.

To help understand the welfare implications of limited attention in the application decision, consider a student who has decided on some fixed number of applications to send and is considering where to send their last application. Because of limited attention, this student is substantially more likely to apply to an IHE ranked in the range of 41-50 relative to an IHE ranked in the range of 51-60. However, as we have shown, there are no discontinuous differences in quality between these two sets of IHEs. Moreover, the likelihood of a successful application declines as USNWR improves, making it less likely the student is admitted to an institution of similar quality. ${ }^{24}$ The decline in the likelihood of admission is exacerbated by the added competition from other students who are applying to the IHEs ranked 4150 as the limited attention problem we demonstrate is a market-wide phenomenon. The decline in admissions probability for the student at an IHE ranked 41-50, and the missing application that would 
have occurred at a school in the 51-60 range, make it more likely the marginal student ends up with a worse quality match, perhaps at an IHE outside of the top 60.

To demonstrate the scale of students who may end up worse off due to their limited attention, consider that National Universities ranked 41-50 receive 27,023 applications on average and Liberal Arts Colleges ranked 41-50 receive 4322 applications on average. RD estimates from Table 7 suggest that limited attention is responsible for an approximate $3 \%$ drop in applications for National Universities that rank at 51 or higher, or about 800 applications per affected IHE. Likewise, results in Table 7 indicate that limited attention accounts for an approximate $5 \%$ decline in applications for Liberal Arts Colleges that rank at 51 or higher, or around 350 missing applications per affected IHE. At the average admit rates of National Universities ranked 51-60, about 416 of the 800 missing applications would have been admitted. Similarly, around 196 of the missing 350 applications to Liberal Arts Colleges would have been admitted. Using an average yield rate for National Universities ranked 51-60 of 34\% and an average yield rate for Liberal Arts Colleges ranked 51-60 of 30\%, we can surmise that around 140 (58) more students would have chosen to attend each of the National Universities (Liberal Arts Colleges) ranked 51-60 in the absence of limited attention. The open question is where exactly these students finally enroll. Some likely end up in better ranked schools, such as those ranked 41-50, because students are overreacting to a top 50 ranking. Surely others end up in schools ranked worse than 60 because of their failure to apply to IHEs ranked just worse than 50 . Our back of the envelope calculations suggest that, over our 10 year study period, potentially thousands of students have found themselves worse off because of limited attention to rankings.

Furthermore, we can provide an approximate idea of the importance of limited attention relative to other IHE attributes. National Universities ranked 51-60 receive 22,066 applications on average which is 4957 fewer applications than those ranked $41-50$. Therefore, we can attribute roughly $16 \%$ of the difference in applications between these two groups to limited attention and the remaining $84 \%$ of the application differences to other IHE attributes such as differential quality or size. Analogously, for Liberal Arts Colleges, IHEs ranked between 51 and 60 receive 3115 applications, which is 1207 fewer applications on average than IHEs between 41 and 50 receive. Hence, nearly $30 \%$ of the decline in applications between these two groups of Liberal Arts Colleges is due to limited attention.

We have explained throughout that it is prospective students who are exhibiting limited attention; however, an alternative explanation is that another agent in the education or labor market displays limited attention and prospective students are behaving accordingly in response. For example, employers could proxy applicants' quality with the rank of their undergraduate institutions. It could be that employers use a decision heuristic such as "top-50" in deciding who to interview or hire. If students perfectly internalized this information, we could observe the same discontinuity in their application decisions at the ranking threshold of 50 . We believe that this is an unlikely primary driver of the results for several reasons. First, this would require that prospective college students perfectly internalize this information, which seems unlikely given the other behavioral biases that have been documented in the behavioral economics of education literature. Secondly, we would expect to find more robust evidence of discontinuities at the rankings thresholds of 10 or 100 if it were another agent such as employers driving the result. That we find the most robust evidence of a discontinuity at 50 
suggests that it is the physical page break in the printed guide that is most important. Moreover, the estimated discontinuity at the threshold of 50 decreases over time while evidence suggests that printed guides concurrently became relatively less important over time. Nevertheless, we cannot completely rule out the possibility that other agents exhibit similar limited attention to rankings. This could indeed be one reason why we find some suggestive evidence of a discontinuous drop in applications at the threshold of 100 .

RD offers an average treatment effect around the threshold of 50 for USNWR rankings, calling into question external validity of the findings outside of a narrow range around the threshold. While the results cannot be used to say that the same magnitude of effect happens in other settings, we submit that the 50 threshold is just one of multiple thresholds that could affect application decisions. The threshold at 50 may be particularly salient because of the printed USNWR page cutoff, but it is likely some students utilize other rankings thresholds to guide their decisions. Therefore, our findings of limited attention may have implications for student matching throughout the rankings continuum.

\section{Appendix A}

Table A1. Regression Results: Effects of Rankings Thresholds on Applications.

\section{Varying Polynomial Order}
(1)
(2)
(3)
(4)
(5)

Threshold

\begin{tabular}{llllll}
$>10$ & $-0.0176^{*}$ & 0.000954 & 0.0147 & 0.00889 & 0.00710 \\
& $(0.00939)$ & $(0.0109)$ & $(0.0143)$ & $(0.0137)$ & $(0.0134)$ \\
$>50$ & $-0.0219^{* *}$ & $-0.0207^{* *}$ & $-0.0283^{* *}$ & $-0.0277^{* *}$ & $-0.0320^{* *}$ \\
& $(0.0102)$ & $(0.00999)$ & $(0.0120)$ & $(0.0119)$ & $(0.0134)$ \\
$>100$ & -0.00855 & $-0.0225^{*}$ & -0.0165 & -0.0144 & -0.0102 \\
& $(0.01000)$ & $(0.0125)$ & $(0.0144)$ & $(0.0154)$ & $(0.0170)$ \\
\multirow{2}{*}{ Polynomial Order } & 2 & 3 & 5 & 6 & 7 \\
Observations & 2613 & 2613 & 2613 & 2613 & 2613 \\
R-squared & 0.987 & 0.987 & 0.987 & 0.987 & 0.987
\end{tabular}

Notes: Robust standard errors in parentheses are clustered at the IHE level.

$* * * \mathrm{p}<0.01, * * \mathrm{p}<0.05, * \mathrm{p}<0.1$.

Regression specifications for all columns include the 1-year lag of logged applications, indicators for Carnegie classification, IHE sector, and year.

Table A2. Local Linear RD Results at Ranking Threshold of 50 with Manual Bandwidths.
(1)
(2)
(3)
(4)
(5)
(6)

Conventional

$-0.0404^{* *}-0.0368^{* *}$

$-0.0323^{* *}-0.0290^{* *}$

$-0.0267^{* *}-0.0230^{* *}$

(0.0162) (0.0165)

(0.0128) (0.0132)

(0.0108) (0.0113)

Bias-Corrected

$$
-0.0605^{* * *}-0.0529^{* * *}
$$$$
-0.0488^{* * *}-0.0453^{* * *}
$$$$
-0.0439^{* * *}-0.0401^{* * *}
$$

$$
(0.0162) \quad(0.0165)
$$

$(0.0128) \quad(0.0132)$

$(0.0108) \quad(0.0113)$ 

(1)
(2)
(3)
(4)
(5)
(6)

$\begin{array}{lllllll}\text { Bias-Corrected Robust } & -0.0605^{* *} & -0.0529^{*} & -0.0488^{* *} & -0.0453^{* *} & -0.0439^{* * *}-0.0401^{* *} \\ & (0.0277) & (0.0288) & (0.0208) & (0.0212) & (0.0171) & (0.0173) \\ \text { BW Selection } & \text { Manual } & \text { Manual } & \text { Manual } & \text { Manual } & \text { Manual } & \text { Manual } \\ \text { Order Local Poly } & 1 & 1 & 1 & 1 & 1 & 1 \\ \text { Order Bias } & 2 & 2 & 2 & 2 & 2 & 2 \\ \text { BW Local Poly } & 20 & 20 & 30 & 30 & 40 & 40 \\ \text { BW Bias } & 20 & 20 & 30 & 30 & 40 & 40 \\ \text { Effective Observations } & 747 & 662 & 1117 & 1001 & 1504 & 1362 \\ \text { Additional Time-Varying } & & \text { Exp./Student, } & & \text { Exp./Student, } & & \text { Exp./Student, } \\ \text { Controls } & & \text { SAT } & & \text { SAT } & & \text { SAT }\end{array}$

Notes: Triangular kernel used in all columns.

Standard errors in parentheses. BW = bandwidth.

Cluster-robust nearest neighbor variance estimator, clustered at the IHE level, is used for "Robust" standard errors in all columns.

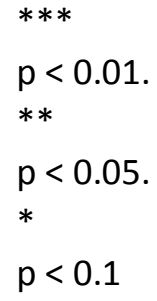

Table A3. Local Linear RD Results at Ranking Threshold of 50 with Uniform Kernel.
(1)
(2)
(2)
(4)
(6)

\begin{tabular}{|c|c|c|c|c|c|}
\hline Conventional & $-0.0398^{* *}$ & $-0.0657^{* *}$ & $-0.0379^{* * *}$ & $-0.0304^{* * *}$ & $-0.0178^{*}$ \\
\hline & $(0.0194)$ & $(0.0320)$ & $(0.0141)$ & $(0.0113)$ & $(0.0095)$ \\
\hline Bias-Corrected & $-0.0446^{* * *}$ & $-0.0680^{* *}$ & $-0.0405^{* * *}$ & $-0.0361^{* * *}$ & $-0.0391^{* * *}$ \\
\hline & $(0.0194)$ & $(0.0320)$ & $(0.0141)$ & $(0.0113)$ & $(0.0095)$ \\
\hline Bias-Corrected Robust & $-0.0446^{* *}$ & $-0.0680^{* *}$ & $-0.0405^{*}$ & $-0.0361^{* *}$ & $-0.0391^{* * *}$ \\
\hline & $(0.0227)$ & $(0.0335)$ & $(0.0245)$ & $(0.0183)$ & $(0.0151)$ \\
\hline BW Selection & MSE & CER & Manual & Manual & Manual \\
\hline Order Local Poly & 1 & 1 & 1 & 1 & 1 \\
\hline Order Bias & 2 & 2 & 2 & 2 & 2 \\
\hline BW Local Poly & 12.66 & 8.88 & 20 & 30 & 40 \\
\hline N Bias & 23.25 & 24.45 & 20 & 30 & 40 \\
\hline Effective Observations & 465 & 303 & 813 & 1165 & 1543 \\
\hline
\end{tabular}

Notes: Uniform kernel used in all columns.

Standard errors in parentheses are clustered at the IHE level. BW $=$ bandwidth, MSE $=$ MSE-optimal, CER $=$ CERoptimal. 
Cluster-robust nearest neighbor variance estimator, clustered at the IHE level, is used for "Bias-Corrected Robust" standard errors in all columns.

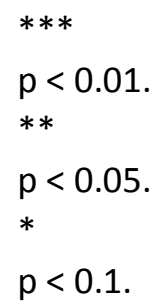

Table A4. Local Quadratic RD Results at Ranking Threshold of 50.
(1)
(2)
(3)
(4ap)

Conventional

$-0.0699^{* *}-0.0412^{*}-0.0442^{* * *}-0.0391^{* * *}$

$\begin{array}{lllll}(0.0306) & (0.0244) & (0.0171) & (0.0151)\end{array}$

Bias-Corrected

$-0.0783^{* * *}-0.0485^{* *}-0.0529^{* * *}-0.0500^{* * *}$

$$
\begin{array}{lllll}
(0.0306) & (0.0244) & (0.0171) & (0.0151)
\end{array}
$$

Bias-Corrected Robust $-0.0783^{* *}-0.0485^{*}-0.0529^{* *}-0.0500^{* *}$

$$
\begin{array}{llll}
(0.0353) & \text { (0.0282) (0.0249) (0.0222) }
\end{array}
$$

Kernel Triangular Uniform Triangular Uniform

$\begin{array}{lllll}\text { BW Selection } & \text { MSE } & \text { MSE } & \text { Manual } & \text { Manual } \\ \text { Order Local Poly } & 2 & 2 & 2 & 2 \\ \text { Order Bias } & 3 & 3 & 3 & 3 \\ \text { BW Local Poly } & 17.24 & 20.41 & 40 & 40 \\ \text { BW Bias } & 24.60 & 30.44 & 40 & 40 \\ \text { Effective Observations } 664 & 813 & 1504 & 1543\end{array}$

Notes: Standard errors in parentheses are clustered at the IHE level. BW = bandwidth, MSE = MSE-optimal, Cluster-robust nearest neighbor variance estimator, clustered at the IHE level, is used for "Bias-Corrected Robust" standard errors in all columns.

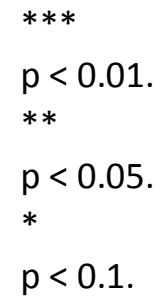




\section{References}

Anderson and Magruder, 2012 M. Anderson, J. Magruder. Learning from the crowd: regression discontinuity estimates of the effects of an online review database. Econ. J., 122 (563) (2012), pp. 957-989.

Andrews et al., 2016 R. Andrews, J. Li, M. Lovenheim. Quantile treatment effects of college quality on earnings. J. Hum. Resour., 51 (1) (2016), pp. 200-238.

Bettinger et al., 2012 E. Bettinger, B. Long, P. Oreopoulos, L. Sanbonmatsu. The role of application assistance and information in college decisions: results from the H\&R block FAFSA experiment. Q. J. Econ., 127 (3) (2012), pp. 1205-1242.

Bowman and Bastedo, 2009 N. Bowman, M. Bastedo. Getting on the front page: organizational reputation, status signals, and the impact of U.S. news and world report on student decisions. Res. Higher Educ., 50 (5) (2009), pp. 415-436.

Busse et al., 2013 M. Busse, N. Lacetera, D. Pope, J. Silva-Risso, J. Sydnor. Estimating the effect of salience in wholesale and retail car markets. Am. Econ. Rev., 103 (3) (2013), pp. 575-579.

Calonico et al., 2014a S. Calonico, M. Cattaneo, R. Titiunik. Robust nonparametric confidence intervals for regression-discontinuity designs. Econometrica, 82 (6) (2014), pp. 2295-2326.

Calonico et al., 2014b S. Calonico, M. Cattaneo, R. Titiunik. Robust data-Driven inference in the regression-discontinuity design. Stata J., 14 (4) (2014), pp. 909-946.

Calonico et al., 2016a Calonico, S., Cattaneo, M., Farrell, M. 2016. On the Effect of Bias Estimation on Coverage Accuracy in Nonparametric Inference. Working Paper.

Calonico et al., 2016b S. Calonico, M. Cattaneo, H. Farrell, R. TitiunikRegression Discontinuity Using Covariates. University of Michigan. Working Paper.

Calonico et al., 2016c S. Calonico, M. Cattaneo, H. Farrell, R. Titiunik. rdrobust: Software for Regression Discontinuity Designs. Working Paper.

Carree and Kronenberg, 2014 M. Carree, K. Kronenberg. Locational choices and the costs of distance: empirical evidence for dutch graduates. Spatial Econ. Anal., 9 (4) (2014), pp. 420-435.

Cattaneo et al., 2016a M. Cattaneo, M. Jansson, X. Ma. Simple Local Regression Distribution Estimators with an Application to Manipulation Testing. Working paper.

Cattaneo et al., 2016b M. Cattaneo, M. Jansson, X. Ma. rddensity: Manipulation Testing Based on Density Discontinuity. Working paper.

Chetty et al., 2009 R. Chetty, A. Looney, K. Kroft. Salience and taxation: theory and evidence. Am. Econ. Rev., 99 (4) (2009), pp. 1145-1177.

Conlin et al., 2007 M. Conlin, T. O’Donoghue, T. Vogelsang. Projection bias in catalog orders. Am. Econ. Rev., 97 (4) (2007), pp. 1217-1249.

Costa and Kahn, 2000 D. Costa, M. Kahn. Power couples: changes in the locational choice of the college educated, 1940-1990. Q. J. Econ., 115 (4) (2000), pp. 1287-1315

Dale and Krueger, 2014 S. Dale, A. Krueger. Estimating the effects of college characteristics over the career using administrative earnings data. J. Hum. Resour., 49 (2) (2014), pp. 323-358.

DellaVigna, 2009 S. DellaVigna. Psychology and economics: evidence from the field. J. Econ. Lit., 47 (2) (2009), pp. 315-372.

Ferber and Green, 2003 M. Ferber, C. Green. Career or family: what choices do college women have? J. Labor Res., 24 (1) (2016), pp. 143-151. 
Finkelstein, 2009 A. Finkelstein. E-ZTax: tax salience and tax rates. Q. J. Econ., 124 (3) (2009), pp. 9691010.

Gnolek et al., 2014 S. Gnolek, V. Falciano, R. Kuncl. Modeling change and variation in US news \& world report college rankings: what would it really take to be in the top 20? Res. Higher Educ., 55 (8) (2014), pp. 761-779.

Griffith and Rask, 2007 A. Griffith, K. Rask. The influence of the US News and World Report collegiate rankings on the matriculation decision of high-ability students: 1995-2004. Econ. Educ. Rev., 26 (2) (2007), pp. 244-255.

Hahn et al., 2001 J. Hahn, P. Todd, W. Van der Klaauw. Identification and estimation of treatment effects with a regression-discontinuity design. Econometrica, 69 (1) (2001), pp. 201-209.

Heller, 1997 D. Heller. Student price response in higher education: an update to Leslie and Brinkman. J. Higher Educ., 68 (6) (1997), pp. 624-659.

Hoekstra, 2009 M. Hoekstra. The effect of attending the flagship state university on earnings: a discontinuity-based approach. Rev. Econ. Stat., 91 (4) (2009), pp. 717-724.

Imbens and Kalyanaraman, 2012 G. Imbens, K. Kalyanaraman. Optimal bandwidth choice for the regression discontinuity estimator. Rev. Econ. Stud., 79 (3) (2012), pp. 933-959.

Koch et al., 2015 A. Koch, J. Nafziger, H. Nielsen. Behavioral economics of education. J. Econ. Behav. Org., 115 (2015), pp. 3-17.

Lacetera et al., 2012 N. Lacetera, D. Pope, J. Sydnor. Heuristic thinking and limited attention in the car market. Am. Econ. Rev., 102 (5) (2012), pp. 2206-2236.

Lavecchia et al., 2016 A. Lavecchia, H. Liu, P. Oreopoulos. Behavioral economics of education: progress and possibilities. E. Hanushek, S. Machin, L. Woessmann (Eds.), Handbook of the Economics of Education, vol. 5, Elsevier, Amsterdam (2016).

Lee and Lemieux, 2010 D. Lee, T. Lemieux. Regression discontinuity designs in economics. J. Econ. Lit., 48 (2) (2010), pp. 281-355.

Leslie and Brinkman, 1987 L. Leslie, P. Brinkman. Student price response in higher education: the student demand studies. J. Higher Educ., 58 (2) (1987), pp. 181-204.

Luca and Smith, 2013 M. Luca, J. Smith. Salience in quality disclosure: evidence from the U. S: news college rankings. J. of Econ. Manage. Strategy, 22 (1) (2013), pp. 58-77.

Luca and Smith, 2015 M. Luca, J. Smith. Strategic disclosure: the case of business school rankings. J. Econ. Behav. Org., 112 (2015), pp. 17-25.

McCrary, $2008 \mathrm{~J}$. McCrary. Manipulation of the running variable in the regression discontinuity design: a density test. J. Econometrics, 142 (2) (2008), pp. 698-714.

Meredith, 2004 M. Meredith. Why do universities compete in the ratings game? an empirical analysis of the effects of the USNWR college rankings. Res. Higher Educ., 45 (5) (2004), pp. 433-461.

Monks and Ehrenberg, 1999 J. Monks, R. Ehrenberg. U.S. news and world report's college rankings: why do they matter? Change, 31 (6) (1999), pp. 42-51.

Oreopoulos and Salvanes, 2011 P. Oreopoulos, K. Salvanes. Priceless: the nonpecuniary benefits of schooling. J. Econ. Perspect., 25 (1) (2011), pp. 159-184.

Pallais, 2015 A. Pallais. Small differences that matter: mistakes in applying to college. J. Labor Econ., 33 (2) (2015), pp. 493-520.

Papay et al., 2016 J. Papay, R. Murnane, J. Willett. The impact of test score labels on human-capital investment decisions. J. Hum. Resour., 51 (2) (2016), pp. 357-388. 
Pope, 2009 D. Pope. Reacting to the rankings: evidence from 'America's best hospitals. J. Health Econ., 28 (6) (2009), pp. 1154-1165.

Pryor et al., 2009 J. Pryor, S. Hurtado, L. DeAngelo, L. PaluckiBlake, S. Tran. The American Freshman: National Norms Fall 2009. Higher Education Research Institute, UCLA, Los Angeles (2009).

Schwartz and Mare, 2005. C. Schwartz, R. Mare. Trends in educational assortative marriage from 1940 to 2003. Demography, 42 (4) (2005), pp. 621-646.

Smith et al., 2014 J. Smith, M. Hurwitz, J. Howell. Screening mechanisms and student responses in the college market. Econ. Educ. Rev., 44 (1) (2014), pp. 17-28.

${ }^{1}$ The application process for undergraduate education in the U.S. is decentralized. Potential students complete applications (typically including an application fee) for each institution they are interested in attending. For most institutions, the decision is then made as to whether or not the student will be admitted into the institution overall, as opposed to being admitted into a specific program.

${ }^{2} \mathrm{~A}$ long literature examines the effect of college attendance on several outcomes including career opportunities (Ferber and Green, 2003), geographic mobility (Costa and Kahn, 2000, Carree and Kronenberg, 2014), earnings (Andrews et al., 2016, Dale and Krueger, 2014, Hoekstra, 2009), spousal matching (Schwartz and Mare, 2005), and overall happiness (Oreopoulos and Salvanes, 2011).

${ }^{3}$ Monks and Ehrenberg (1999) document an association between IHE rankings and applications. Meredith (2004) leverages panel data from 1991 to 2000 and estimates an IHE fixed-effects model to find that several admissions outcomes change when IHEs move within the top 25 or between the first two quartiles of rankings. Griffith and Rask (2007) also find some evidence that students are more likely to attend IHEs with better rankings.

${ }^{4}$ Koch et al. (2015) and Lavecchia et al. (2016) review the behavioral economics of education literature.

${ }^{5}$ Gnolek et al. (2014) provide an extensive discussion of the literature on the USNWR rankings.

${ }^{6}$ For examples, see Bettinger et al. (2012), Pallais (2015), Papay et al. (2016), and Smith et al. (2014).

${ }^{7}$ We find some anecdotal evidence to support this claim via a Google search. For each IHE ranked in the 2016 guide, we searched for "(IHE name) usnews ranking" and then examined the first page of search results. We then followed any links to the given IHE's website. We found one National University and one Liberal Arts College that categorically identify their ranking as "top 10" rather than that focusing on the specific ranking. Similarly, we found 4 National Universities and 4 Liberal Arts Colleges that emphasize the categorical ranking of "top 100" over the specific numerical ranking. Moreover, until recently, the "list view" on the USNWR website displayed the top 10 ranked IHE's on the first page. We also found two IHEs that list "top 25" on their website. Moreover, some non-USNWR rankings only include the "top 25 " so we also investigated a potential threshold at 25 . See Section 3.1 for further details. 
${ }^{8}$ For more specific information on how the rankings are constructed please see https://www.usnews.com/education/best-colleges/articles/rankings-methodologies.

${ }^{9}$ Our sample covers the period from 2004 to 2013. We collect information on applications for fall 2003 to include information on lagged applications in our subsequent analysis.

${ }^{10}$ The Carnegie classification is a commonly recognized system used to categorize U.S. IHEs based on the types of degrees awarded and level of research activity. For more information please see http://carnegieclassifications.iu.edu/

${ }^{11}$ SAT scores are missing for approximately $10 \%$ of our observations in the IPEDs database so including this variable does somewhat change the composition of our sample.

${ }^{12}$ We estimate this model with IHE fixed effects as a robustness check but it is not our preferred specification because there is little within-IHE variation in treatment status. For example, on average, there are just over 2 IHEs that move into (and out of) the top-50 in each year. The RD literature has shown that the variance of the estimator can increase when this is the case (Lee and Lemieux, 2010).

${ }^{13}$ We also estimated specifications identical to those reported in Table 3 but adding an indicator for crossing the threshold of 25 . We do not find any evidence of a discontinuity at the 25 -threshold. Coefficient estimates on the indicator for crossing the 25-threshold are close to 0 and not statistically significant. Adding the 25 -threshold only slightly changes the point estimates of the discontinuity at the 50-threshold, but not the statistical significance. These results are available upon request.

\footnotetext{
${ }^{14} \mathrm{We}$ allow the regression function to take on different slopes on both sides of the threshold. For example, the conventional RD estimator with linear controls and a uniform kernel is given by the specification,
}

${ }^{15} \mathrm{RD}$ estimation has been mostly viewed as a nonparametric estimation problem since Hahn et al. (2001) because the functional form is unknown and misspecification of the functional form in RD can lead to a large bias in the RD estimate of the treatment effect (Lee and Lemieux, 2010).

${ }^{16} \mathrm{~A}$ mean squared error (MSE) expansion of the local linear RD estimator includes both the variance of the estimator and the bias of the estimator.

${ }^{17}$ We use the rdrobust package within Stata for all RD estimation (Calonico et al., 2016b). Papay et al. (2016) also utilize local linear regression. Hahn et al. (2001) originally suggest using local linear regressions to reduce bias (Lee and Lemieux, 2010).

${ }^{18} \mathrm{After}$ showing that both variance estimators produce similar results in Table 6, we adopt the cluster robust nearest neighbor variance estimator (clustering at the level of the IHE) for the remainder of the paper. Results using other variance estimators are similar and available upon request. 
${ }^{19}$ Two specifications in Table A3, Table A4 produce point estimates that are somewhat larger in absolute value but they also have larger standard errors.

${ }^{20}$ As noted by Lee and Lemieux (2010), where $Y$ denotes the outcome variable, "finding a discontinuity in $Y_{i t}$ but not in $Y_{i t-1}$ would be a strong piece of evidence supporting the validity of the RD design."

${ }^{21}$ We specifically use the test proposed by Cattaneo et al. (2016a), which improves upon the widely utilized McCrary (2008) test. We use the default options of the Cattaneo et al. (2016a) test as implemented in the rddensity package (Cattaneo et al., 2016b).

${ }^{22}$ The results are weighted to be approximately representative of the national population of first-time, full-time, first-year students.

${ }^{23}$ According to Google Trends, "us news college rankings" and "college application" are the most popular search queries related to the corresponding topics. The Google Trends data are normalized so that "a value of 100 is the peak popularity for the term. A value of 50 means that the term is half as popular." We limit the geographic area to the United States.

${ }^{24}$ We conduct a parallel RD analysis using the admit rate as the dependent variable in place of applications and find a discontinuity in the admit rate at the threshold of 50. For the MSE-optimal bandwidth, we find that the admit rate increases by 2 percentage points when moving from inside the top 50 to outside the top 50 (significant at the $5 \%$ level). Included baseline covariates include the lag of admit rate, year fixed effects, a dummy for private versus public IHE, and a dummy for a Carnegie classification of a bachelors institution. Full results on admit rate are available upon request. 